This is an electronic reprint of the original article. This reprint may differ from the original in pagination and typographic detail.

Author(s): Huttunen, Kristiina; Kellokumpu, Jenni

Title: $\quad$ The Effect of Job Displacement on Couples' Fertility Decisions

Year: $\quad 2016$

Version:

Please cite the original version:

Huttunen, K., \& Kellokumpu, J. (2016). The Effect of Job Displacement on Couples' Fertility Decisions. Journal of Labor Economics, 34(2), 403-442.

https://doi.org/10.1086/683645

All material supplied via JYX is protected by copyright and other intellectual property rights, and duplication or sale of all or part of any of the repository collections is not permitted, except that material may be duplicated by you for your research use or educational purposes in electronic or print form. You must obtain permission for any other use. Electronic or print copies may not be offered, whether for sale or otherwise to anyone who is not an authorised user. 


\title{
The Effect of Job Displacement on Couples' Fertility Decisions
}

\author{
Kristiina Huttunen, Aalto University, HECER, and IZA
}

\author{
Jenni Kellokumpu, University of Jyväskylä
}

\begin{abstract}
This paper analyzes the effects of job displacement on fertility using Finnish longitudinal register data. We focus on couples where one spouse has lost a job due to a plant closure and follow them for several years before and following the job loss. The results show that female job loss decreases fertility. For every 100 displaced females, there are three fewer children born. Male job loss has no impact on fertility despite resulting in a stronger decrease in family income than female job loss. This indicates that the income effect is not the mechanism through which job displacement influences fertility.
\end{abstract}

\section{Introduction}

The question of how income affects people's fertility behavior has interested economists for decades. The evidence points in various directions. Cross-sectional studies suggest that family size is negatively related to household income, while studies investigating changes in aggregate wages

We would like to thank Joshua Angrist, David Autor, Christina Gathmann, Stephen Machin, Jukka Pirttila, Jörn-Steffen Pischke, Kjell Salvanes, Till von Wachter, and Roope Uusitalo for very useful comments, as well as the participants in the following workshops and seminars: EALE, EEA, NBER Summer Institute, ELE, MIT, LSE/CEP, SOLE, Tinbergen Institute, and IFAU. We are grateful for financial support from the Palkansaaja-Foundation, the Yrjö Jahnsson Foundation, and the Finnish Academy. Contact the corresponding author, Kristiina Huttunen, at kristiina.huttunen@aalto.fi. Information concerning access to the data used in this article is available as supplementary material online.

[Journal of Labor Economics, 2016, vol. 34, no. 2, pt. 1]

(C) 2016 by The University of Chicago. All rights reserved. 0734-306X/2016/3402-0004\$10.00

Submitted July 3, 2012; Accepted November 7, 2014; Electronically published January 19, 2016 
or unemployment find that better economic conditions increase the demand for children. The literature suffers from various challenges. A household's income and fertility tend to be jointly determined, which makes it difficult to disentangle the causal mechanism between income and fertility. Some studies have focused on exogenous changes in aggregate income in order to mitigate the problems of reverse causality (Schultz 1985; Black et al. 2013). The use of aggregate measures may, however, hide important heterogeneity in responses. According to the standard economic theory of fertility, the distinction between male and female income is crucial since women are assumed to be more likely the ones who take time off from work to participate in the care of young children.

This article examines the effect of job loss that is due to plant closure on a couple's fertility behavior. A plant closure can be thought of as an exogenous shock to a worker's career since it results in a separation of all of the plant's workers and is not related to the worker's own job performance. Several studies have documented that displaced workers suffer from longlasting earnings losses (Jacobson, LaLonde, and Sullivan 1993; Eliason and Storrie 2006; Couch and Placzek 2010; Huttunen, Møen, and Salvanes 2011). Thus, we can use plant closures to explore the causal effect of male and female income shocks on fertility behavior at the micro level.

We acknowledge that a job loss can have an indirect effect on a couple's fertility decisions through mechanisms other than income changes. The career interruption itself may affect fertility since it increases uncertainty concerning future employment conditions and job instability (Stevens 1997, 2001; Farber 2007). Job displacement can also influence fertility behavior through several noneconomic outcomes, such as divorce probability (Charles and Stephens 2004; Eliason 2012) and health (Martikainen, Mäki, and Jäntti 2007; Sullivan and von Wachter 2009). In order to make distinctions among these alternative channels, we investigate the effect of job loss on various outcomes, such as earnings, family income, employment, spouse's employment, employment stability, and divorce.

We use Finnish longitudinal employer-employee data (FLEED) matched to birth records to analyze the effect of a job loss on fertility. The data consist of all 16-70-year-old Finnish residents from 1988 to 2004. Each worker and his or her employer in these data have a unique identification code. In addition, information on workers' spouses is included, which makes it possible to create a sample of (cohabiting or married) couples. ${ }^{1}$ We focus on couples where one spouse lost his or her job due to a plant closure in the years 1991-93. As a comparison group, we use similar couples

${ }^{1}$ We use the word spouse to mean both spouses in married couples and partners in unmarried cohabiting couples. Cohabitation (before marriage) is common in Finland. 
who were not affected by a plant closure. We follow each couple for 4 years before a job loss and for 11 years after a job loss in order to investigate the changes in their fertility over the period.

This paper makes several contributions both to family economics and to literature that examines the impacts of job displacements. First, we can distinguish between a woman's own and her spouse's job loss, and thus we can make a distinction between a shock to the woman's career and an income shock generated by the man's job loss. Previous studies have either focused on the effect of a woman's own job loss (Del Bono, Weber, and Winter-Ebmer 2012) or the effect of a husband's job loss (Lindo 2010) on fertility. Second, the long time span allows us to distinguish between the effect on fertility postponement and completed fertility and to analyze the effect on various long-term outcomes, such as permanent family income. Finally, in addition to comparing responses by spouses, the rich data allow us to examine the heterogeneity of responses by various other observational dimensions, such as education, tenure, and spouse's education. We use our theoretical framework to interpret how the effect of job displacement on fertility may vary by worker characteristics.

The results show that a woman's job loss decreases fertility and that the effect is strongest for highly educated women. For every 100 displaced highly educated females, there are five fewer children born. Despite the larger reduction in permanent income $(-3.63 \%$ vs. $-2.72 \%)$, male job loss has a much weaker effect on fertility than female job loss. The only groups for which we find significant responses after male job loss are the couples in which the women are well attached to the labor market and couples with the largest estimated income loss: the low-educated, hightenure males. This suggests that the income effect is not the main mechanism through which job loss influences couples' fertility behavior. Career concerns, especially in the case of highly educated women, seem to be a much more important determinant.

The paper proceeds as follows. Section II presents a brief theoretical background and gives an overview of the existing literature. In Section III, we describe the data and the institutions, and we provide some descriptive evidence. Section IV outlines the empirical set up, presents the results, and summarizes the implications of our estimates. Section V concludes.

\section{Background and Previous Evidence}

In this section, we describe the basic theoretical framework for the analysis. We start by reviewing how income affects fertility behavior and then discuss the alternative mechanisms through which job displacement can affect fertility. We then summarize the previous empirical literature on the effects of income and employment changes on fertility. 


\section{A. Theoretical Background}

In the traditional model of fertility (see, e.g., Becker 1960, 1965), a reduction of a woman's own wage (a woman's job loss) can affect fertility through income and substitution effects. If children are normal goods, reduction in income reduces fertility (income effect). However the wage reduction (or unemployment) makes the value of a woman's time cheaper and reduces the opportunity costs of having children. This substitution effect increases fertility. The overall effect is ambiguous and depends on the relationship between market wages and the profitability of home production. In this traditional static model, a man's earnings changes affect fertility only through the income effect since men are not assumed to take time off from work to participate in the care of young children (see, e.g., Heckman and Walker 1990). The quantity-quality model (Becker 1960; Becker and Lewis 1973) extends this basic model so that parents' demand for the children consists of both the demand for the number of children and the demand for child quality (expenditure on education). An increase in income can increase the expenditure on child quality without increasing the number of children.

The effect of the income shock may also differ between workers of different characteristics. Perry (2004) uses the static model of household production introduced by Gronau (1977) to illustrate how a woman's wage changes affect fertility decisions for different skill groups. For high-wage women who initially spend little time in home production, a decrease in earnings will only affect the consumption of goods and thus decrease fertility since the income effect dominates. For low-wage women, the wage reduction may even increase fertility since the substitution effect dominates. A dynamic model of fertility can help us to understand the possible heterogeneity in the income effect further. In a dynamic framework, the effect of earnings on fertility depends on whether the effect is transitory or permanent and on whether the individuals are credit constrained or not (see, e.g., Hotz, Klerman, and Willis 1993). Under perfect capital markets (i.e., no one is credit constrained), a transitory effect should not have an effect on fertility. However, for credit-constrained households, a transitory effect may affect the spacing of children since such households want to postpone childbearing to periods when incomes are higher. A permanent effect on earnings affects the completed fertility.

Job displacement can influence a couple's fertility decisions through mechanisms other than income changes. The career break itself can influence a worker's fertility decisions. A worker may want to continue into a new employment relationship without breaks and fear that a child or a pregnancy may decrease the chances of finding new employment (Del Bono et al. 2012). Job displacement also increases the uncertainty concerning the future employment conditions since it increases temporary employment 
relationships and subsequent job displacements (Stevens 1997, 2001; Farber 2007). This uncertainty can reduce parents' desired fertility. Finally, job loss may have an indirect effect on fertility through increased risk of divorce (Charles and Stephens 2004; Rege, Telle, and Votruba 2007; Eliason 2012) and by increased health risk (Browning, Moller Dano, and Heinesen 2006; Martikainen et al. 2007) and mortality (Eliason and Storrie 2009; Sullivan and von Wachter 2009).

Career interruptions may influence workers from different skill categories differently if the rate of skill appreciation differs by workers' skill level. However, the evidence on the effect of skills on human capital depreciation is mixed. Some studies (e.g., Adda, Dustmann, and Stevens 2011) show that human capital depreciation is higher in abstract jobs that employ more highly skilled workers. However, the job displacement literature has documented that highly educated workers tend to have shorter nonemployment spells and suffer less severe earning losses after job displacement (Stevens 1997; von Wachter and Weber Handverker 2010). These studies argue that skilled workers have more transferable human capital and a better ability to re-accumulate skills faster.

To sum up, we expect job displacement to affect fertility through various mechanisms. The effect is likely to vary both between spouses and by a worker's skill level. If we expect that the effect of job displacement influences fertility mainly through income changes, the reduction in fertility after a male's job displacement should be stronger than the reduction after a female's job loss (since females' earnings changes work both through substitution and income effects). The effect can vary by a worker's skill level as well, although the direction of heterogeneity of the effect is ambiguous. If job displacement influences the fertility decision through career breaks and concerns, then female job loss should have a stronger impact on fertility than male job loss since females are more likely to take time off from work after a child birth.

\section{B. Previous Literature}

A vast literature has investigated how income affects household's fertility behavior. The majority of the cross-sectional evidence both across countries and with individuals indicates a clear negative correlation between income and fertility. For example, Jones and Tertilt (2008) document a negative and surprisingly stable cross-sectional relationship between income and fertility in the United States over several decades and estimate an overall income elasticity of about -0.38 . As stated in a review by Hotz et al. (1993), the key challenge in the empirical literature on fertility is how to obtain exogenous variation in households' income and in the prices of children. Earlier studies either ignored this or, as did Heckman and Walker (1990), used aggregate wages to mitigate the problems of reversed 
causality. Their results indicate that rising female wages delay and reduce overall fertility, whereas male wages have at most a small positive effect on fertility.

The previous attempts to estimate a causal effect of income changes on fertility behavior have exploited exogenous variation in aggregate female and male wages stemming from some exogenous shocks. Schultz (1985) uses exogenous variation in relative female and male wages arising from the changes in the world price of butter relative to the world price of grains in Sweden in the early twentieth century. Since dairy and milk processing were "women's work" in Sweden, the relative increase in the world price of butter increased female wages relative to male wages. Schultz shows that the increase in female relative wages decreased fertility, while the increases in real male wages had no effect on total fertility. Black et al. (2013) use the exogenous shocks to men's income in coal counties in the United States that was caused by the coal boom in 1970s to investigate the causal effect of income on fertility. Their findings suggest that a $10 \%$ increase in income increased fertility by $7 \%$. Lovenheim and Mumford (2013) investigate the effect of the family's life-time wealth on fertility. They exploit the variation in housing prices in the United States caused by the housing boom that began in the late 1990s and that affected differentially housing prices across different locations. They find that short-run increases in one's home value are associated with an increase in the probability of having a child, suggesting a housing wealth elasticity of fertility of 0.13 .

There have been many fewer attempts to investigate the effects of employment and earnings shocks on fertility behavior at the micro level. Lindo (2010) uses the Panel Study of Income Dynamics (PSID) to examine the effect of male job loss on fertility. He finds that male job loss increases fertility in the years immediately after job loss but that the effect becomes negative for years 3-8 after job loss. The total effect on fertility by the eighth year is negative, although it is not statistically significant when individual fixed effects are included in the model. The estimated effect of male job loss on annual earnings by the eighth year since job loss is around $-31.6 \%$, which together with the $4.8 \%$ reduction in total fertility in post-displacement years implies an income elasticity of 0.15 .

Del Bono et al. (2012) examine the effects of a woman's own job loss using Austrian data from 1972 to 2002. Comparing the birth rates of displaced women with those unaffected by job losses, they find that job displacement reduces average fertility by $5 \%$ and $10 \%$ in the short and medium terms ( 9 years after job loss). The strong average response is mainly explained by the behavior of white-collar women. Although the study focuses on women, it also uses as a robustness check a small subsample of men in order to examine how male job loss influences fertility behavior. Male job loss decreases fertility, although the point estimates are 
slightly smaller than those for females. Del Bono et al.'s interpretation is that it is not only the loss of income that causes fertility to decline but also the career interruption that occurs due to the displacement. ${ }^{2}$

Another branch of the literature has investigated how fertility responds to downturns and high unemployment. ${ }^{3}$ Most of these studies in both demographics and economics support the idea that fertility is procyclical, since there is a clear negative relationship between aggregate unemployment and fertility (Ahn and Mira 2001; Adsera 2005; Sobotka, Skirbekk, and Philipov 2011). Dehejia and Lleras-Muney (2004) study the relationship between unemployment rate and selection into motherhood. They find that the fertility response to temporary shocks in income differs substantially by socioeconomic status and by race in the United States. They argue that this reflects the fact that women who are more likely to be credit constrained (low-educated black women) have an incentive to postpone childbearing when the unemployment rate is high, while notcredit-constrained low-skilled women (low-educated white women) tend to increase fertility in recessions.

Overall, there are relatively few studies that have examined how career shocks or income shocks affect fertility at the micro level. The previous attempts to analyze causal effect of income on fertility have either focused on changes in aggregate wages or on short-term responses. The previous studies that have examined the effect of job displacement on fertility have either focused on male or female job displacement, and they have not investigated the effects on long-term outcomes of both spouses, such as permanent family income, joint employment decisions, or divorce.

\section{Institutions, Data, and Descriptive Evidence}

\section{A. Institutional Background}

All workers who lose their jobs are entitled to unemployment benefits in Finland. In addition, workers who have been working and contributing insurance payments to an unemployment fund for 10 months during the 2 years prior to unemployment are entitled to earnings-related unemployment benefits. Most workers in Finland contribute to insurance payments either through the labor unions or through unemployment insurance institutions. The average replacement rate is $60 \%$. The maximum length of

${ }^{2}$ Del Bono et al. (2010) provide descriptive evidence showing that there is a significant gap in quarterly earnings of displaced women and the comparison group in the first 3 years after job loss, but they cannot follow earnings in time.

${ }^{3}$ There also exist studies that have examined how government transfer policies and subsidies causing exogenous changes in the price of children affect household's fertility decisions. Milligan (2005) and Cohen, Dehejia, and Romanov (2013) find that child subsidies have a positive effect on fertility. 
earnings-related UI is 500 days (23 months). After this, workers are entitled to labor market support. All parents in Finland are eligible for earningsrelated parental allowance. The parental allowance is calculated using the previous year's annual taxable labor income, and the average compensation is $75 \%$ of previous earnings. The length of the parental leave is 263 days (10.5 months).

\section{B. Data}

The empirical analysis is based on a panel data set from Statistics Finland that links information on employees, establishments, and firms. The data include all Finnish residents who were 16-70 years old in the years 1988-2004. The data have unique individual, spouse (cohabiting partner), plant, and municipality codes that can be used to merge additional information from other registers. Information on childbirths is drawn from the population registers provided by Statistics Finland. It has information on the time of birth and the gender of the child.

We focus on married or cohabiting couples in which the woman was 20-40 years old and the man was $20-50$ years old in the year preceding possible job loss, that is, in a base year $t$. When examining the effect of a women's own job loss, we restrict the analysis to women with at least 1 year of tenure working in a private sector plant with 5-1,000 workers, who did not give birth in year $t$, and whose parental or unemployment benefits did not exceed their annual earnings in base year $t .{ }^{4}$ When analyzing the effect of a man's job displacement, we take men with at least 1 year of tenure working in a private sector plant with 5-1,000 workers, whose parental or unemployment benefits did not exceed their annual earnings, and whose spouse (woman) did not give birth in base year $t$. In order to better compare the effects of female and male job losses on fertility, we also form a third sample, where we require both spouses to be employed in year $t$.

We then divide workers into displaced and nondisplaced workers, using the plant closure definition in year $t$ : a plant is a closing plant in year $t$ if it is in the entire register data in year $t$ but is no longer there in year $t+1$ or in any of the years after $t+1$. To make sure that these are real closures, we define those exiting plants for which more than $70 \%$ of the workforce is working in a single new plant in the following year as not real closures. A displaced worker is a worker who was separated between $t$ and $t+1$ from a plant that closed down during this time. In addition, we take so-called early-leavers, that is, workers who left between $t$ and $t+1$ from plants that closed down between $t+1$ and $t+2$ and that reduced their size more than $30 \%$ between $t$ and $t+1$. As a robustness check, we also use an alternative definition of job displacement: a job loss that results from a

\footnotetext{
${ }^{4}$ The employment information is from the last week of the year.
} 
mass layoff event. This means that a worker is labeled as displaced in year $t$ if he or she separated between $t$ and $t+1$ from a plant that downsizes more than $30 \%$ between $t$ and $t+1$. Since small plants are much more likely to have relatively large employment fluctuations, we follow the previous literature and take workers in plants with more than 50 (and less than 2,500 ) workers in base year $t$ when using this job displacement definition.

After having defined a worker's displacement status in base year $t$, we follow each worker and his or her spouse 3 years before a possible job loss until the eleventh year after a job loss. Our main base years are 1991-93, ${ }^{5}$ and we follow workers from these years using the data covering 19882004. The construction of the sample allows us to use the rich information on the pre-displacement period to construct the pre-displacement comparability between those who were affected by the plant closure (treatment group) and those who were not (comparison group). ${ }^{6}$ We investigate differences in several outcomes using all pre-and post-displacement years. Employment is an indicator variable that gets the value one if a worker's employment status is "employed." Annual earnings are measured as annual taxable labor income in year $t$. We also use another income measure, annual taxable income, which includes also transfers such as unemployment and parental benefits. It is important to make a distinction between these two measures since in Finland the level of both unemployment insurance and parental benefits is relatively high. Family income is constructed by adding up both spouses' total taxable income (including transfers). Divorce status is defined using spouse codes. A worker is labeled as divorced if he or she no longer has the same spouse as in base year $t$. We use two different measures for fertility: an indicator variable that a woman has given birth in the current year and the total number of children.

The combined data set has several attractive features. First, it allows us to reliably identify plant closures and downsizing events for the whole economy. Second, we are able to follow both spouses over a long time span and investigate the long-term effect of job displacement on fertility and various other outcomes as well, such as joint employment decisions, family income, and divorce probability.

\section{Descriptive Analysis}

The mean values of pre-displacement characteristics for displaced and nondisplaced workers are presented in table 1 . We also report the $p$-value for the null hypothesis that the means are equal in the two groups. There should be no significant differences between the displaced and nondisplaced

${ }^{5}$ To investigate the robustness of the results to different business cycle conditions, we also redo the analysis for recovery years 1996-98.

${ }^{6}$ Following most recent studies, the comparison group consists of both stayers and workers who separated voluntarily or due to illness, etc. 


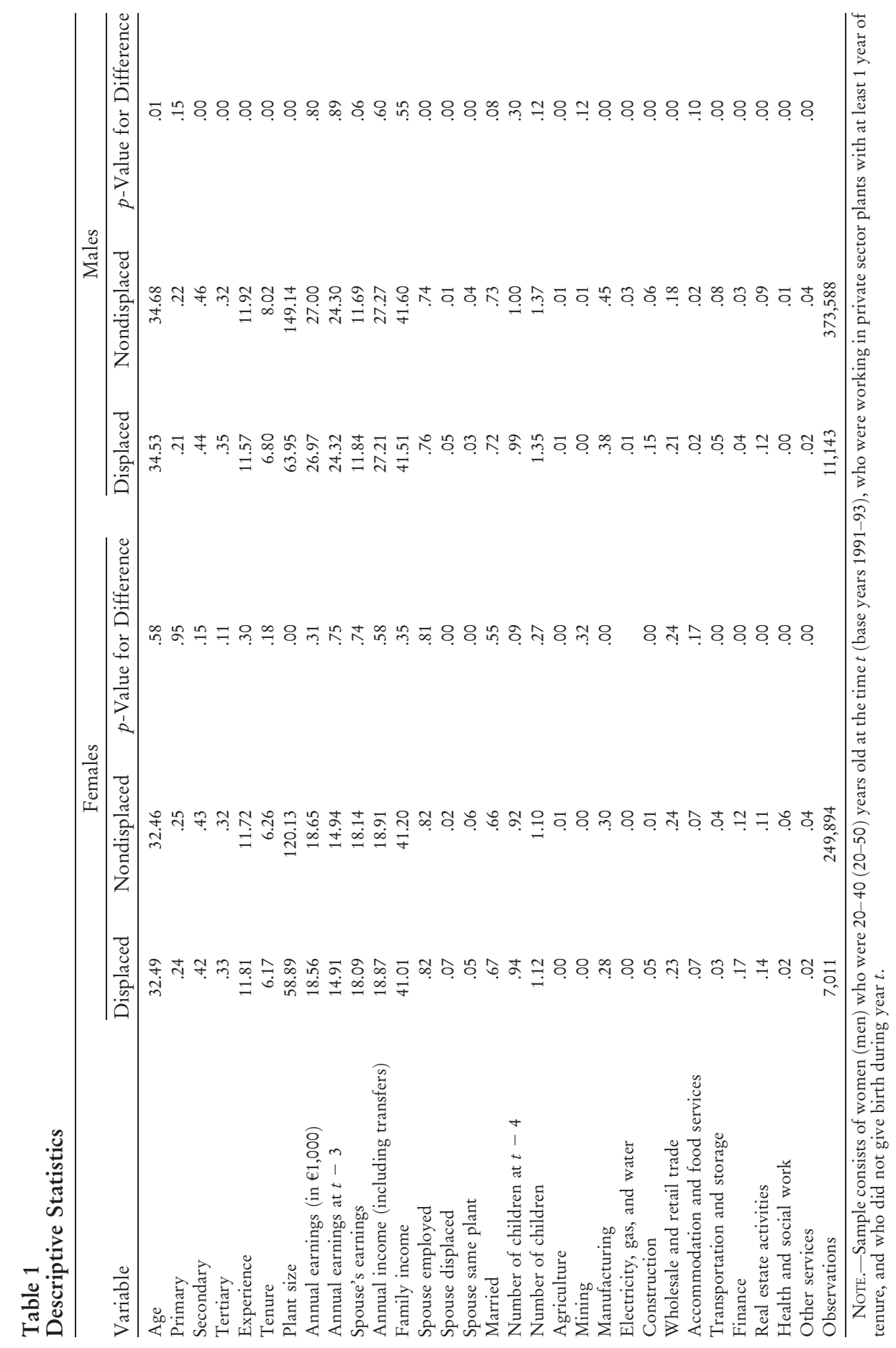

This content downloaded from 130.234.241.107 on January 09, 2017 02:41:12 AM All use subject to University of Chicago Press Terms and Conditions (http://www.journals.uchicago.edu/t-and-c). 
groups since a job loss that is a result of a plant closure should be independent of the worker's own performance. However, the group of displaced workers may be selected if there is selective turnover or if plant closures occur more frequently in regions and industries with certain types of workers.' Table 1 shows that the female workers displaced in plant closures are very similar to nondisplaced workers. The only significant differences are plant size and the probability of the spouse working in the same plant or being displaced. The differences between displaced and nondisplaced male workers are also very small, although the difference is more often significant than in the female sample. The biggest differences are in the plant size and tenure. This reflects that small and young plants are more likely to die. Displacements are also more frequent in some industries. ${ }^{8}$ In the regression analysis, we take into account all possible predisplacement differences in our analysis by conditioning on a rich set of pre-displacement worker and plant characteristics, including plant size and industry dummies. Overall, table 1 suggests that the raw pre-displacement differences between displaced and nondisplaced workers are very small in both data sets, which supports the identification strategy in our paper.

To illustrate the shock created by job displacement, we follow both displaced and nondisplaced workers several years before and after job loss and report the average annual earnings (including zeros) for these groups in the upper panel of figure 1. The earnings of the two groups are very similar before job loss, which indicates that job displacement was an exogenous shock to these workers. Job displacement reduces the earnings of displaced workers and opens up a significant earnings gap between displaced and nondisplaced workers. In line with previous findings, the earnings difference between the displaced and the nondisplaced begins a couple of years before the job loss occurs. One obvious reason for a big drop in annual earnings is the loss of earnings that is due to nonemployment. The lower panel of figure 1 shows the share of employed workers among displaced and nondisplaced workers in years preceding and succeeding job loss. In the first year after job displacement, there is a significant drop in the employment level of displaced workers. Of workers who are displaced in

7 To investigate whether there is any selective turnover before closure, we report the mean values of average worker characteristics in different pre-closure years in online appendix B . There are small changes occurring in worker composition, but these are not very different than changes occurring in surviving plants that are followed at the same time.

${ }^{8}$ In order to ensure the comparability of our treatment and comparison group, we also drop workers working in two-digit industries with a displacement rate lower than $0.05 \%$. For females, this is $4.5 \%$ of the observations, and for males it is $6 \%$ of the observations. 
A

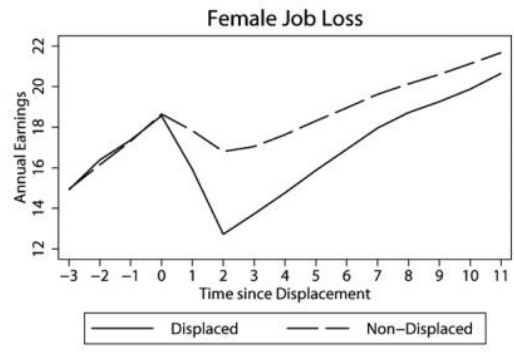

B

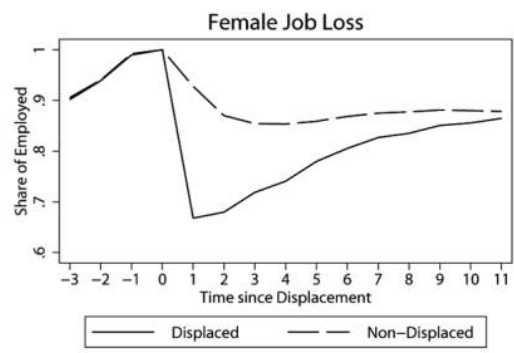

Male Job Loss

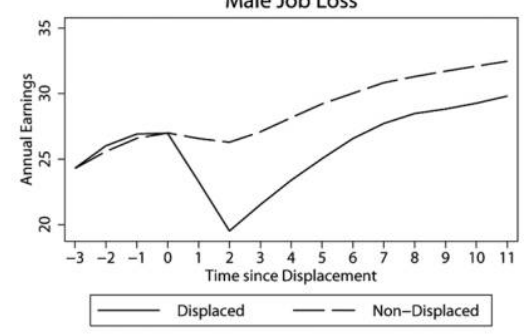

Male Job Loss

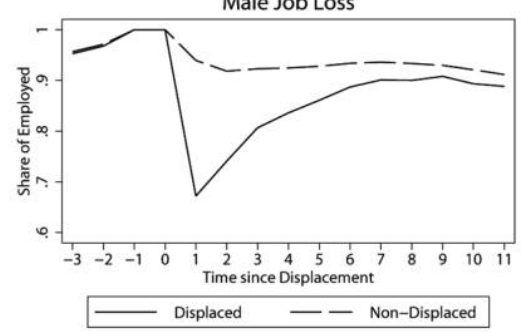

Fig. 1.-Annual earnings $(A)$ and employment share $(B)$ by displacement status. Solid lines describe the outcome of displaced workers. Dotted lines are the outcome of nondisplaced workers.

plant closures, 67\% are re-employed by the following year. There is an important drop in the employment rate of the comparison group as well, especially in the female sample. It is important to remember that these workers were displaced during a very severe recession, which explains the relatively low re-employment rate compared to previous studies.

In the upper panel of figure 2, we report the birth rates of displaced and nondisplaced worker groups. Female displaced workers are less likely to give birth in years around the job loss event than nondisplaced workers. ${ }^{9}$ We see no difference in birth rates between displaced and nondisplaced male workers. In the lower panel, we report the number of children for the displaced and nondisplaced groups. ${ }^{10}$ Displaced women have slightly more children than nondisplaced women in the years preceding job loss, as shown also in table 1 . This difference in the number of children diminishes and becomes negative over time. For males, displaced workers have fewer children throughout the period, but the difference is not significant. There is no change in the difference in the number of children after

\footnotetext{
${ }^{9}$ Note that we exclude workers who gave birth in year $t$.

${ }^{10}$ The birth information is linked to males using the base-year spouse's ID codes.
} 
A

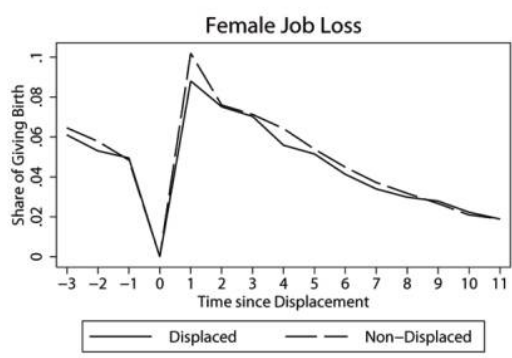

B

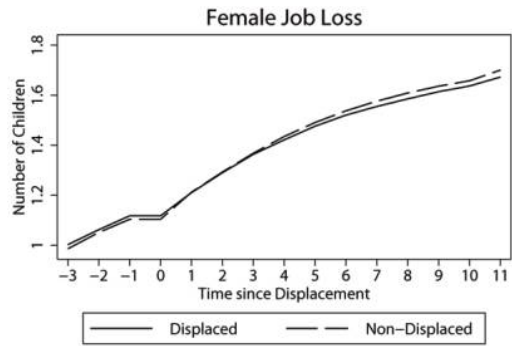

Male Job Loss

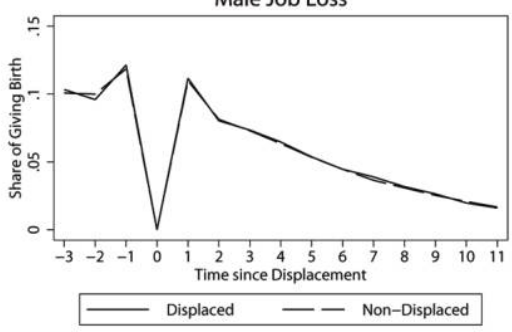

Male Job Loss

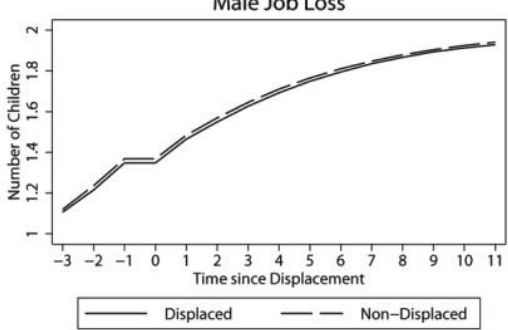

FIG. 2.- Share of giving birth $(A)$ and cumulative number of children $(B)$ by displacement status. Solid lines describe the outcome of displaced workers. Dotted lines are the outcome of nondisplaced workers.

job loss. Next we investigate in a regression framework the effect of job displacement when comparing similar workers within the same industries.

\section{Specification and Results}

A. Empirical Specification

In order to examine the effect of job displacement on fertility and other outcomes, we use a standard approach in the job displacement literature and estimate the following equation:

$$
Y_{i b t}=X_{i b} \beta+\sum_{j=-3}^{11} D_{i b t-j} \delta_{j}+\tau_{b t}\left(+\alpha_{i b}\right)+\varepsilon_{i b t},
$$

where $Y_{i b t}$ is the outcome variable for individual $i$ in base year sample $b$ in year $t$. We use several different outcome measures: annual earnings in $€ 1,000$, annual family income in $€ 1,000$, a dummy for giving birth in a given year, cumulative number of births, a dummy for being employed, a dummy for having an employed spouses, post-displacement tenure, and a dummy for having divorced from the pre-displacement partner. Expression $X_{i b}$ is a vector of the observable worker and firm characteristics: the only time-varying characteristics is worker's age, age squared (or in some specifications a full set of age dummies); all other controls are from the pre-displacement (base) year: a dummy for education level (6 categories), 
a dummy for education field (10 categories), years of tenure, tenure squared, marital status, the spouse's employment status, the spouse's earnings in base year, the spouse's age and age squared, the number of children 4 years before base year, plant size, and region (21 categories) and two-digitindustry dummies. In addition, the model has a full set of time dummy $\times$ base year dummy interactions $\left(\tau_{b t}\right)$.

The model is estimated using all pre- and post-displacement years. The main variable of interest is the displacement variable $D_{i t-j .}$ This is a dummy variable indicating whether a displacement occurs at time $t-j, t$ being the observation year. A job loss is assumed to affect labor market outcomes 4 years before its occurrence and 11 years after its occurrence; hence, $j=$ $-3,11$. Our estimation method relies on the assumption that job displacement event $D_{i b t-j}$ is an exogenous shock to a worker's career. We also estimate the model with base year-specific individual fixed effects $\alpha_{i b}$ in order to control for the permanent differences in outcome between displaced and nondisplaced. In the fixed effects specification, we use the period $t-3$ as the base line and thus drop the displacement dummy for this year.

We restrict the estimation to married or cohabiting couples (men and women who had a spouse in year $t$ ) and estimate the model separately for each spouse. We also estimate a specification that includes both spouses' job displacement dummies in the same regressions using data of couples who were both employed in year $t$. This way we can better compare the effects of male and female job losses.

\section{B. The Effect of Job Displacement on Income}

To understand the magnitude of income losses associated with job displacement, we investigate how female and male job loss affects the annual and permanent income of couples. We begin by estimating the effect of job loss on own annual earnings (in $€ 1,000)$. The results of specifications with and without individual fixed effects are reported in figure 3. Consistent with previous literature, we find that displacement significantly reduces the earnings of displaced workers. ${ }^{11}$ On average, displaced female workers earn around $€ 3,750$ less in the second post-displacement year than similar nondisplaced workers. This corresponds to a $22 \%$ decrease in earnings. ${ }^{12}$ The significant and negative effect on earnings appears to be long lasting: in the eleventh post-displacement year, displaced workers earn still $€ 689$ less than similar workers in the comparison group. A man's job displacement results in a significant and long-lasting earnings loss as well. The magnitude

11 The biggest drop in earnings is in the second year after a job loss. This is expected since the employment information in the data concerns the last week of the year and the displacement event is occurring some time in year 1 and the earnings are from the whole calendar year.

${ }^{12}$ The percentage loss is obtained by dividing the loss in annual income in year 2 by comparison group annual earnings in year 2 , which is $€ 16,801$. 
A

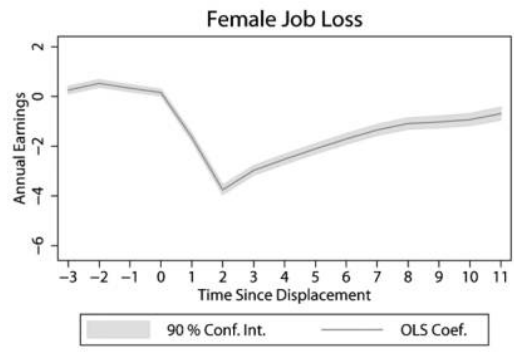

B

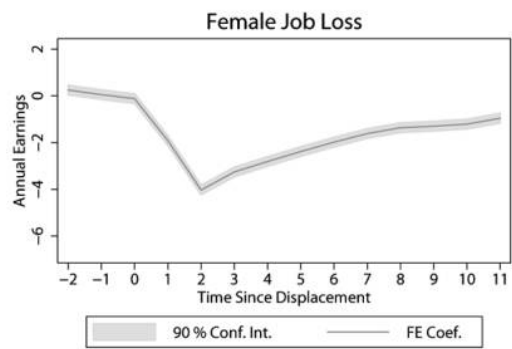

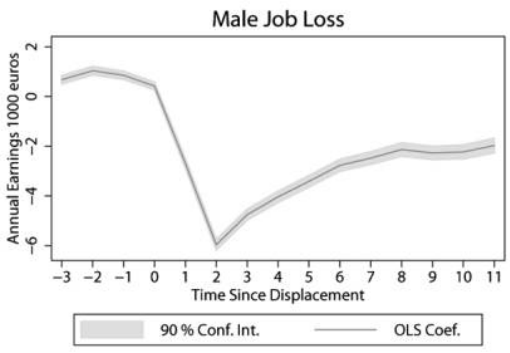

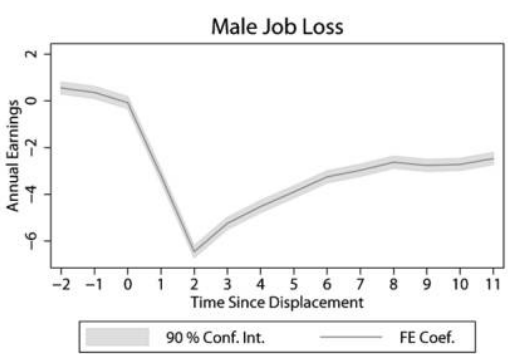

Fig. 3.-Effect of job displacement on annual earnings: without individual fixed effects $(A)$ and with individual fixed effects $(B)$. The $90 \%$ confidence intervals are obtained by clustering standard errors on individuals. Sample consists of women who were 20-40 years old at time 0 (base years 1991-93), who were working in the end of the year 0 and -1 , and who did not give birth during year 0 . The additional control variables in the specification without individual fixed effects are worker's age at the time of displacement, age squared, a dummy for education level (6 categories), a dummy for education field (10 categories), pre-displacement years of tenure, tenure squared, pre-displacement marital status, spouse's employment status in base year, spouse's earnings in base year, spouse's age and age squared, the number of children 4 years before job loss, pre-displacement plant size, pre-displacement region ( 21 categories) and two-digit-industry dummies, and time dummy $\times$ base year dummy interactions. In fixed effects specifications, the controls are time dummy $x$ base year dummy interactions, age, age squared, and spouse's age and spouse's age squared.

of the effect on the second-year earnings is similar in percentage $(23 \%)$, although the gap in euros between displaced and nondisplaced workers is bigger than in the female sample $(-€ 5,960)$. In the eleventh postdisplacement year, displaced workers earnings are still $€ 1,960$ lower than the earnings of similar nondisplaced workers. The fixed effect model indicates a similar reduction in earnings. ${ }^{13}$

13 The fixed effect model indicates a $€ 4,025$ reduction in earnings in the second year after a female job loss, which is a $24 \%$ decrease when comparing that with the counterfactual earnings for displaced workers (calculated as summing the mean for displaced workers minus the estimated effect). The fixed effect of male job loss on second-year earnings is $-€ 6,450(-25 \%)$. 
Since Finland has a high level of unemployment and parental benefits, it is reasonable to focus on total taxable family income rather than just own earnings (from work). Figure 4 presents results of regressions where the outcome variable is annual taxable family income. This is calculated by summing both spouses' annual income, including all benefits and transfers. There is a significant drop in family income immediately after job displacement. For displaced females, the ordinary least squares (OLS) effect is around $4.8 \%(€ 1,840)$. Male job loss results in a much bigger drop in total family income than female job loss $(7.40 \% ; € 3.220)$. The effect is long lasting, although it diminishes over time: in the eleventh postdisplacement year, displaced women have $1.2 \%$ lower family income and males have $2.2 \%$ lower family income than similar comparison group workers. The fixed effects specification gives similar but slightly stronger results. The estimated second-year effect is $-5.3 \%(-€ 2,240)$ for females and $-7.9 \%$ for males $(-€ 3,400)$.

Next we estimate the effect of job displacement on permanent income. Following Davis and von Wachter (2011), we calculate the estimated present discounted value (PDV) earnings losses as

$$
\operatorname{PDV}_{\text {Loss }}=\sum_{s=1}^{11} \delta_{s} \frac{1}{(1+r)^{s-1}}+\sum_{s=12}^{25} \delta_{11} \frac{(1-\lambda)^{s-11}}{(1+r)^{s-1}},
$$

where $\delta_{s}$ is the estimated effect of earnings loss for period $s$ after job displacement. We calculate the present value of earnings loss 25 years after job displacement, and we assume that the losses after the eleventh year (the last period that we observe) decay with similar rate $\lambda$ as between years 10 and $11 .{ }^{14}$ The percentage effect of the PDV earnings loss is obtained by dividing the PDV of earnings loss with PDV of counterfactual earnings in the absence of displacement. The counterfactual earnings path is obtained by adding the value of the estimated earnings loss from fixed effects specification back to average level of earnings for the displaced group each period. Since workers are on average 45 years old at year 11 , and the earnings growth of over 45-year-old workers is relatively stable, we assume that earnings stay at the same level from year 11 until year 25 .

The estimated PDV earnings and family income losses using a 3\% interest rate, $r$, are reported in table 2 . Female job loss decreases the present value of future earnings by $€ 27,904$, which corresponds to a $-7.72 \%$ loss on PDV earnings. The effect of male job loss on PDV earnings is higher both in absolute terms $(-€ 54,967)$ and in percentages $(-10 \%)$. The effect of female job loss on PDV family income (including transfers) is $2.72 \%$, and the effect of male job loss is $3.63 \%$.

${ }^{14}$ The rate of decay that we use is 0.009 , which is the rate at which the effect of job displacement on earnings decreases for males between year 10 and year 11. 
A

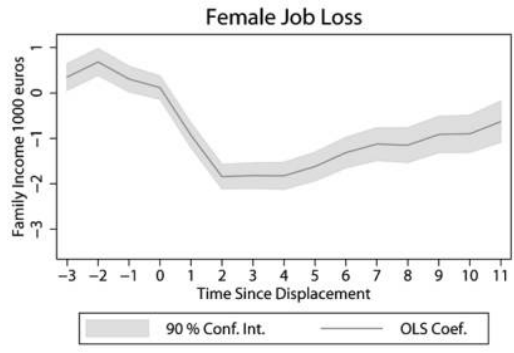

B

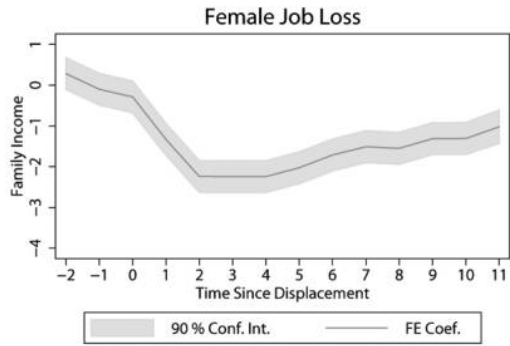

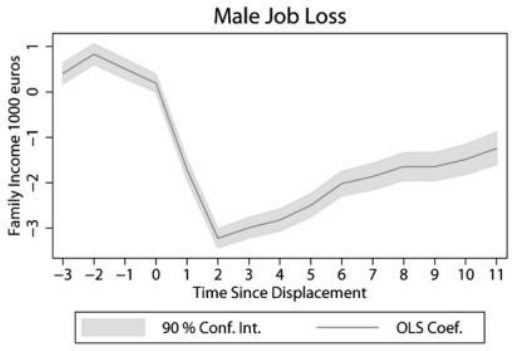

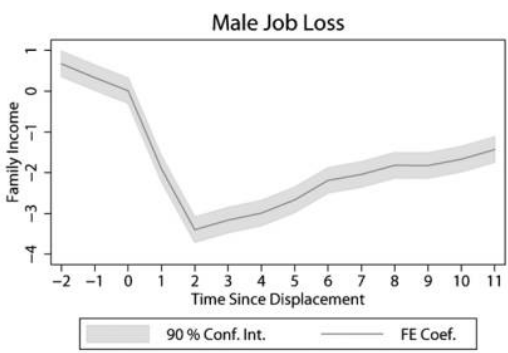

Fig. 4.-Effect of job displacement on annual family income without individual fixed effects $(A)$ and with individual fixed effects $(B)$. The $90 \%$ confidence intervals are obtained by clustering standard errors on individuals. Sample consists of women who were 20-40 years old at time 0 (base years 1991-93), who were working in the end of the year 0 and -1 , and who did not give birth during year 0 . The additional control variables are reported under figure 3 .

Previous research suggests that earnings losses after job displacement differ by pre-displacement tenure (e.g., Tobel 1990) and education (von Wachter and Weber Handverker 2010). For this reason, we split the sample by pre-displacement tenure and education and report the permanent income losses for these groups in table $2 .{ }^{15}$ The corresponding yearby-year effects of job displacement on annual earnings and family income for each group are reported in table A2. In line with previous research, we find that the income losses are largest for low-educated workers and for workers with high pre-displacement tenure. ${ }^{16}$ The group that has the

${ }^{15}$ Low educated refers to group with basic or lower secondary education (maximum of 12 years of schooling). High educated have an upper-secondary degree, such as a college degree (more than 12 years). Low tenure means less and high tenure more than 3 years of pre-displacement tenure.

${ }^{16}$ The effect of job displacement on PDV family income for low- and higheducated females are larger than the effect for all, although the not discounted cumulative effect for years 1-11 for all females $(-3.5 \%)$ lies between the effect of low-educated $(-4.37 \%)$ and high-educated groups $(-3.22 \%)$. The PDV effects put more weight to estimates that are closer to period $t$. 
Table 2

Percentage Loss in Cumulative and PDV Permanent Own and Family Income

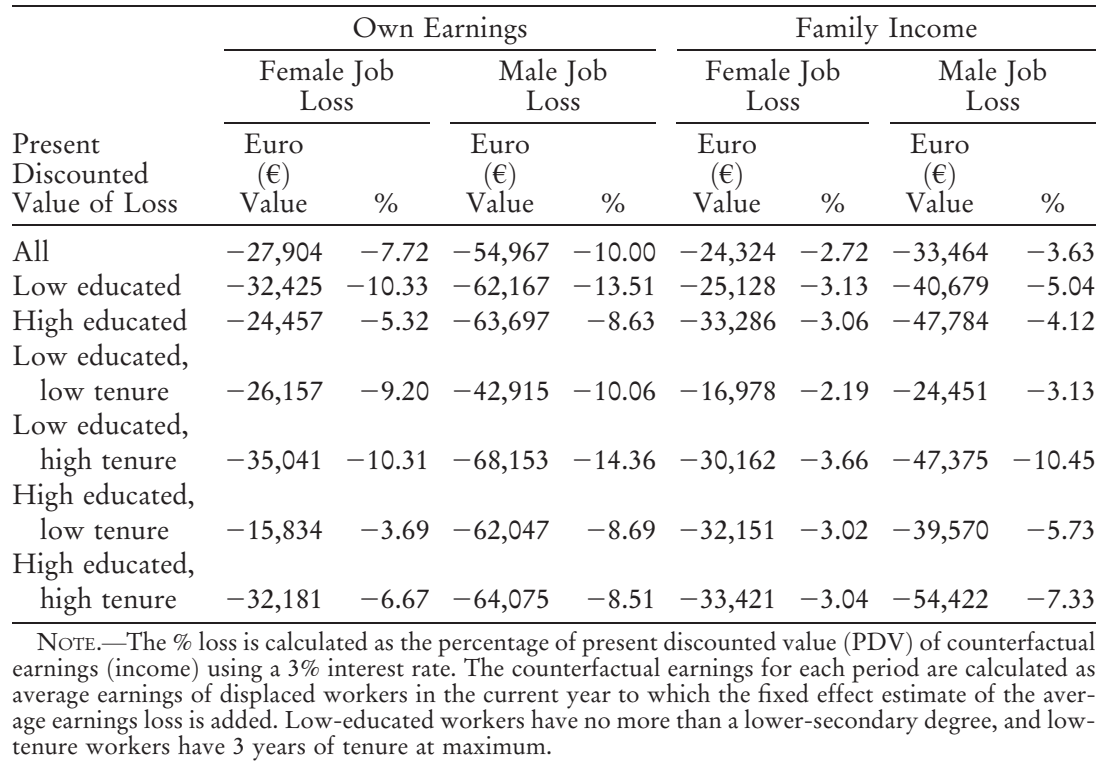

highest permanent income losses after job loss is low-educated, high-tenure workers.

\section{The Effect of Job Displacement on Fertility}

To examine how a woman's own or her spouse's job loss affects fertility, we first estimate the effect on a cumulative number of children using all pre- and post-displacement years. The estimated coefficients on displacement variables are plotted in figure 5 and in table 3. The dependent variable is the number of children by the end of the year. We use the number of children in year $t-4$ as a control variable in order to take account of the permanent differences in fertility between displaced and nondisplaced. ${ }^{17}$ Results indicate that a woman's own job displacement decreases fertility immediately after job loss. The effect is persistent and leads to a significant difference in completed fertility. For every 100 couples with a displaced woman, three fewer children are born by the eleventh year after a job loss than what there would have been in the absence of a woman's job loss. This corresponds to a $1.8 \%$ decrease in fertility. In contrast, male job loss seems to have no effect on fertility postponement or completed

${ }^{17}$ We also estimated the model with individual fixed effects, and the results are reported in online appendix B). 

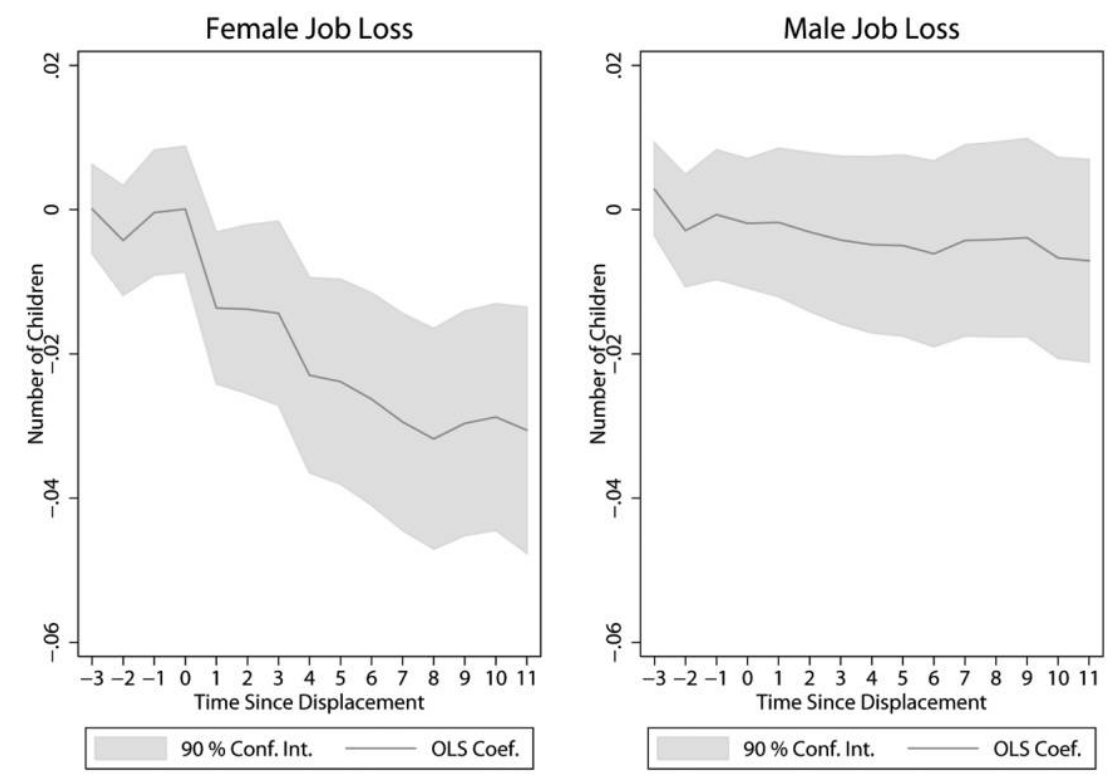

Fig. 5.-Effect of job displacement on cumulative number of children. Sample consists of women (men) who were 20-40 (20-50) years old at time 0 (base years 1991-93), who were working in the end of the year 0 and -1 , and who did not give birth during year 0 and who were married or cohabiting in year 0 . The additional control variables are the full set of worker's age dummies, a dummy for education level (6 categories), a dummy for education field (10 categories), predisplacement years of tenure, tenure squared, pre-displacement marital status, spouse's employment status in base year, spouse's earnings in base year, a full set of spouse's age dummies, the number of children 4 years before job loss, predisplacement plant size, pre-displacement region (21 categories), and two-digitpredisplacement-industry dummies, and time dummies $\times$ base year dummies interactions. The $90 \%$ confidence intervals are obtained by clustering standard errors on individuals.

fertility. There is no significant difference in fertility between male workers who were displaced in plant closures and notdisplaced males.

Table 3 also presents results from an alternative specification that estimates the effect of female job displacement on the probability of giving birth in the current year. Similar to the results of the regression on cumulative number of children, we find that displaced women are less likely to give birth after job displacement. ${ }^{18}$ Women who have lost their job in

18 The reason for the smaller number of observations is that we cannot estimate the effect for years when the outcome variable does not vary. The linear probability model using all years is reported in online appendix B. 


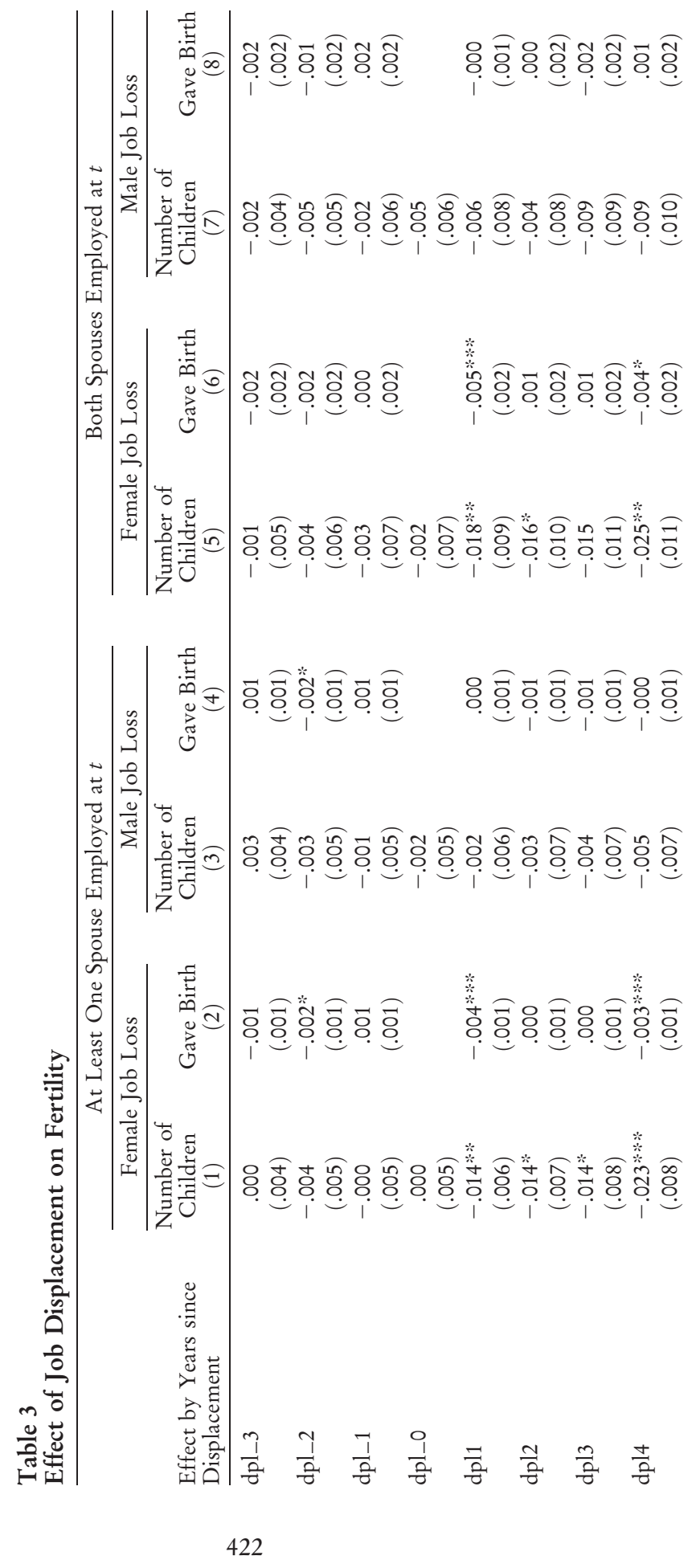

This content downloaded from 130.234.241.107 on January 09, 2017 02:41:12 AM All use subject to University of Chicago Press Terms and Conditions (http://www.journals.uchicago.edu/t-and-c). 


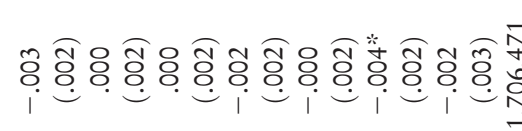

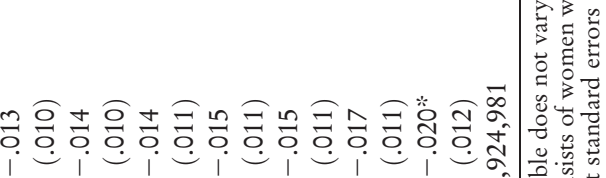

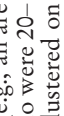

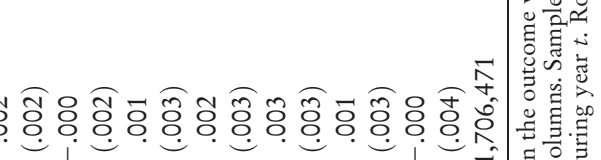

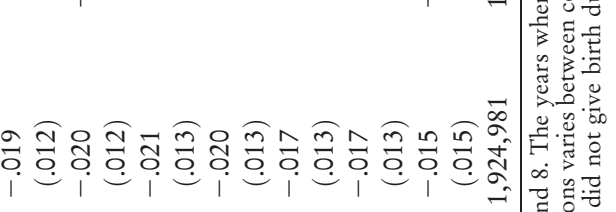

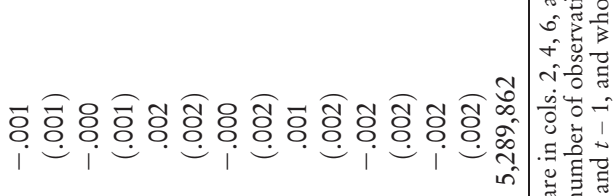

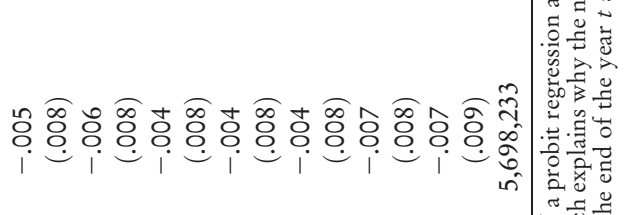

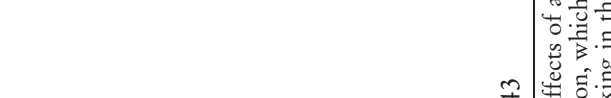

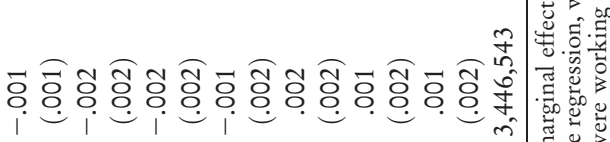

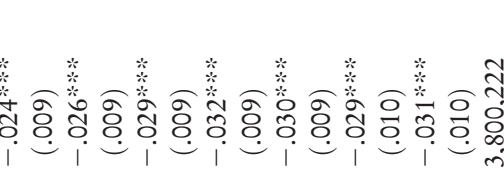

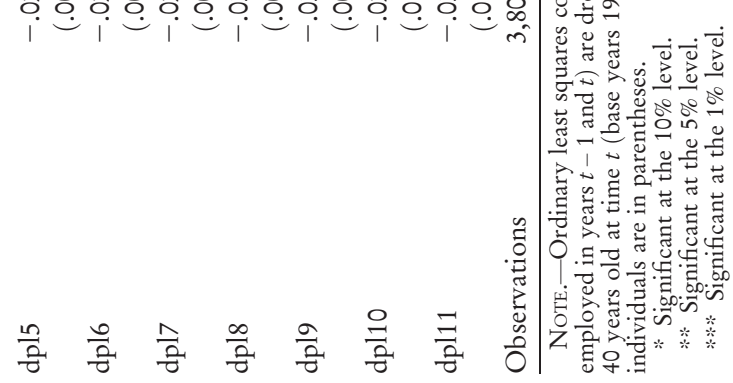


plant closures are $0.4 \%$ less likely to give birth within a year from job displacement than similar nondisplaced women. This represents a $4 \%$ decrease in probability to give birth since the average nondisplaced worker has a $10 \%$ probability of giving birth during this period. This postponement seems to correspond to the effect on the completed fertility as shown in column 1. Male job loss does not affect the probability of his partner giving birth.

In the regressions reported in columns 1-4, we have different samples when analyzing the effects of female and male job losses. In the female job loss sample, we have couples where women were employed in year $t$, and in the male job loss sample, all men were employed in year $t$. These couples may be very different if, for example, couples with nonworking mothers react differently to changes in income than working mothers. In order to better compare the effects of female and male job losses, we restrict the analysis to couples where both spouses were employed in year $t$ and estimate a model where we include dummies for both spouse's displacement status. These results are reported in columns 5-8. Now there seems to be no pre-displacement differences in the likelihood for giving birth, but the immediate effect on the probability of giving birth in the year following a female job loss is now bigger, 0.005 . Male job loss has no immediate effect on fertility, but it results in a small reduction in completed number of children in the long run for this sample. This indicates that in couples where women are well attached to the labor market, a male job loss may also influence fertility.

As argued in Section II, there may be a number of reasons why the effect of job displacement on fertility may differ between skill groups. Figure 6 presents the results where we have split the sample into two groups by education. We find that there is an important heterogeneity in the effect of job displacement on fertility. The effect of job loss is much stronger for highly educated women. The effect remains until the end of the study period. By the eleventh post-displacement year, there are 0.045 fewer children born for displaced highly educated women than for similar nondisplaced women. Highly educated women postpone births after job loss, which corresponds to a $2.6 \%$ reduction in completed fertility. ${ }^{19}$ When studying how the effect of male job loss varies between high- and loweducated males, there seems to be no differences in the response. For both groups, male job displacement does not affect fertility. However, when examining how the responses by male job loss vary by woman's education in

${ }^{19}$ We also examined how the effect varies by pre-displacement wage and the share of a worker's earnings of the total family income (see online appendix B). A woman's job loss reduces the fertility more strongly for high-wage women and for women in households where the husband's share of household income is low. 
A Female Job Loss
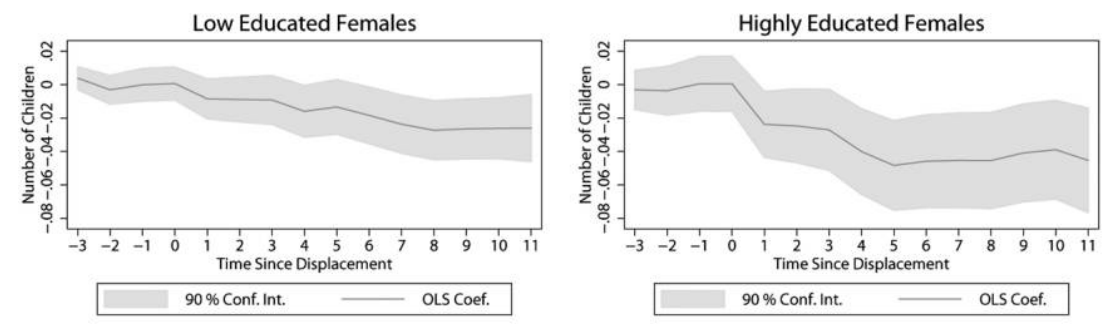

B Male Job Loss
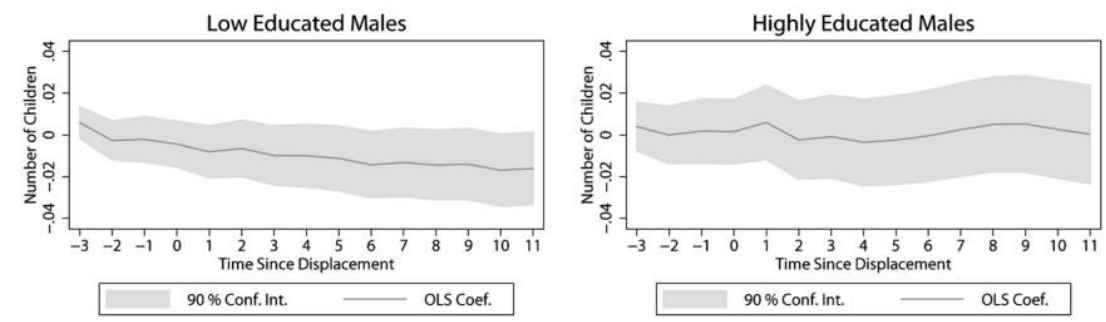

FIG. 6.-Effect of female job displacement on fertility by education. See the text under figure 5.

the sample of employed couple's (fig. 7), we find that couples with highly educated employed females react to both male and female job losses.

In the previous section, we documented that the income loss resulting from a job displacement is highest for low-educated workers with high pre-displacement job tenure. To investigate how these income changes are associated with fertility changes, we now investigate how the fertility effects differ by pre-displacement tenure and education. We calculate the corresponding income elasticity of fertility using the PDV estimates from table 2. Table 4 shows that the strongest reaction from a female job loss on fertility is from highly educated high-tenure women $(3.3 \%)$. The corresponding income loss is, however, the smallest one, as shown in table 2 . In contrast, the only significant effect of male job loss on fertility is for the group for which the associated PDV income loss is largest: high-tenure, low-educated males. For this group, male job displacement reduces fertility by $1.4 \%$. The estimated fertility effects are smaller than found by Lindo (2010) and Del Bono et al. (2012), who find that female job loss reduced fertility by $5 \%-10 \%$ and male job loss by $4.8 \%$. If we assume that the job loss for males works mainly through the income effect, we can calculate that the estimated own earnings elasticity for fertility is 0.10 and family income elasticity is 0.14 . The own income elasticity for this group is smaller 


\section{A Female Job Loss}
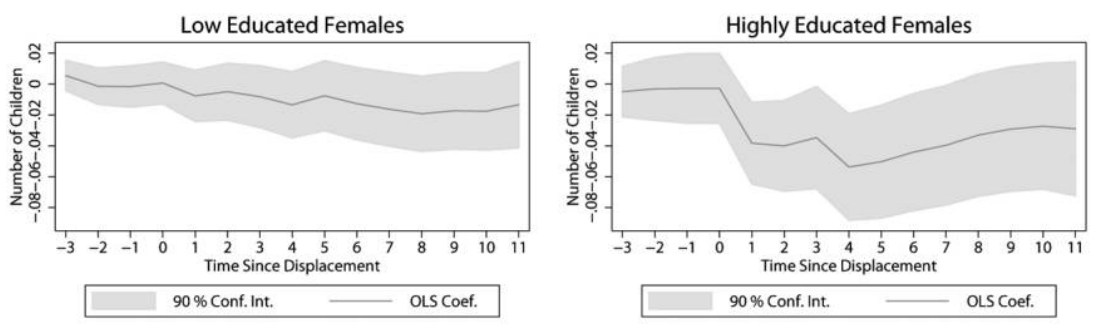

B Male Job Loss
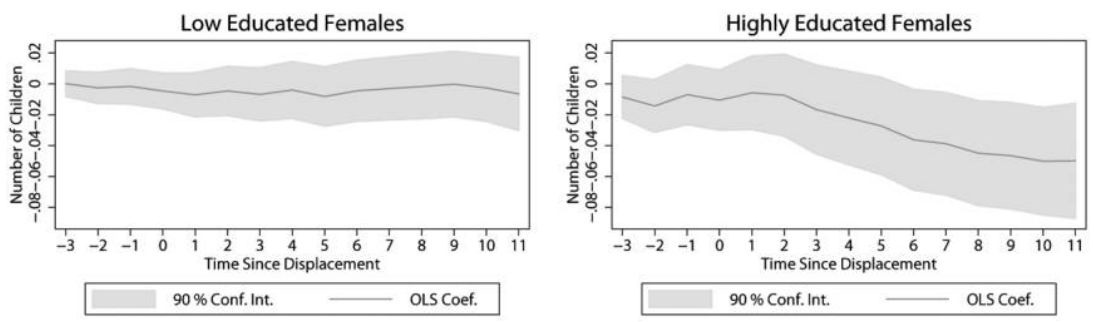

FIG. 7.-Effect of female job displacement on fertility by female education in sample of employed couples. Sample consists of couples, where both spouses were working in the end of the year 0 and -1 . See the text under figure 5 for other details and control variables.

than the average elasticity reported by Lindo (0.015). When calculating the income elasticity of fertility, it is important to bear in mind that job displacement may influence income also through some indirect mechanism (even through fertility changes) and that fertility may be influenced through other channels than income changes.

These results indicate that explanations other than the income effect, such as career concerns, seem to be a much more important determinant after female job loss. We analyze the alternative channels more specifically in the next subsection.

\section{The Effect of Job Displacement on Employment,} Job Stability, and Divorce

To further understand the mechanism through which job displacement influences couples' fertility behavior, we examine in this subsection the effect of job displacement on several other outcomes: joint employment decisions, employment stability, and divorce probability. The first and fifth columns in table 5 report the estimated marginal effects of job displacement on the probability to be employed in the current year. The 
Table 4

Effect of Job Displacement on Cumulative Number of Children and Permanent Income Elasticity

\begin{tabular}{|c|c|c|c|c|c|c|c|c|}
\hline & \multicolumn{4}{|c|}{ Female Job Loss } & \multicolumn{4}{|c|}{ Male Job Loss } \\
\hline & Effect & $\%$ & $\begin{array}{c}\text { Own } \\
\text { Earnings } \\
\text { Elasticity }\end{array}$ & $\begin{array}{c}\text { Family } \\
\text { Income } \\
\text { Elasticity }\end{array}$ & Effect & $\%$ & $\begin{array}{c}\text { Own } \\
\text { Earnings } \\
\text { Elasticity }\end{array}$ & $\begin{array}{l}\text { Family } \\
\text { Income } \\
\text { Elasticity }\end{array}$ \\
\hline All & $-.031 \%$ & -1.76 & .23 & .65 & -.007 & -.36 & .04 & .10 \\
\hline Low educated & $-.026 \%$ & -1.54 & .15 & .49 & -.016 & -.84 & .06 & .17 \\
\hline $\begin{array}{l}\text { High educated } \\
\text { Low educated, }\end{array}$ & $-.045 \%$ & -2.61 & .49 & .85 & .000 & .02 & -.00 & -.00 \\
\hline $\begin{array}{c}\text { low tenure } \\
\text { Low educated, }\end{array}$ & -.021 & -1.17 & .13 & .54 & -.002 & -.13 & .01 & .04 \\
\hline $\begin{array}{c}\text { high tenure } \\
\text { High educated, }\end{array}$ & $-.032 \%$ & -1.99 & .19 & .54 & $-.027 *$ & -1.44 & .10 & .14 \\
\hline $\begin{array}{c}\text { low tenure } \\
\text { High educated, }\end{array}$ & $-.025 \%$ & -1.43 & .39 & .47 & -.027 & -1.38 & .16 & .24 \\
\hline high tenure & $-.057 \%$ & -3.31 & .50 & 1.09 & .015 & .72 & .16 & -.10 \\
\hline
\end{tabular}

NOTE. - The effect is the estimated effect of job displacement on cumulative number of children by the eleventh post-displacement year. The percentage is the effect related to the comparison group mean in the eleventh year. The elasticity is calculated using the percentage loss in PDV of permanent own earnings and family income that is reported in table 2.

* Significant at the $10 \%$ level.

results show that female workers who lose their jobs in plant closures are 0.29 percentage points less likely to be employed at the end of the first post displacement year. Comparing to mean employment in the comparison group (93\%), this corresponds to a $31 \%$ decrease in employment probability. A man's job loss has a slightly smaller but long-lasting effect on employment. In the first post-displacement year, the effect is 24 percentage points; this corresponds to a $25 \%$ decrease in employment probability. The effect decreases over time but remains significant until the eleventh post-displacement year.

Another important mechanism through which fertility may be affected is the increased job instability after permanent job loss. In columns 2 and 6 , we examine how female and male job displacement affects tenure in the post-displacement job. The regression is estimated for post-displacement years only, and the dependent variable is the years in the job since base year $(t=0)$. In the first year, the maximum value is also one for comparison group workers. In order to distinguish from general employment effects, we restrict the sample to individuals who were re-employed by the end of the first post-displacement year. This creates an additional selection problem, since displaced workers who manage to be re-employed within a year may be positively selected among displaced workers and also among all workers who were employed in the year 1 . The estimates are likely to be the lower bound of the effect. The results show that displaced workers 


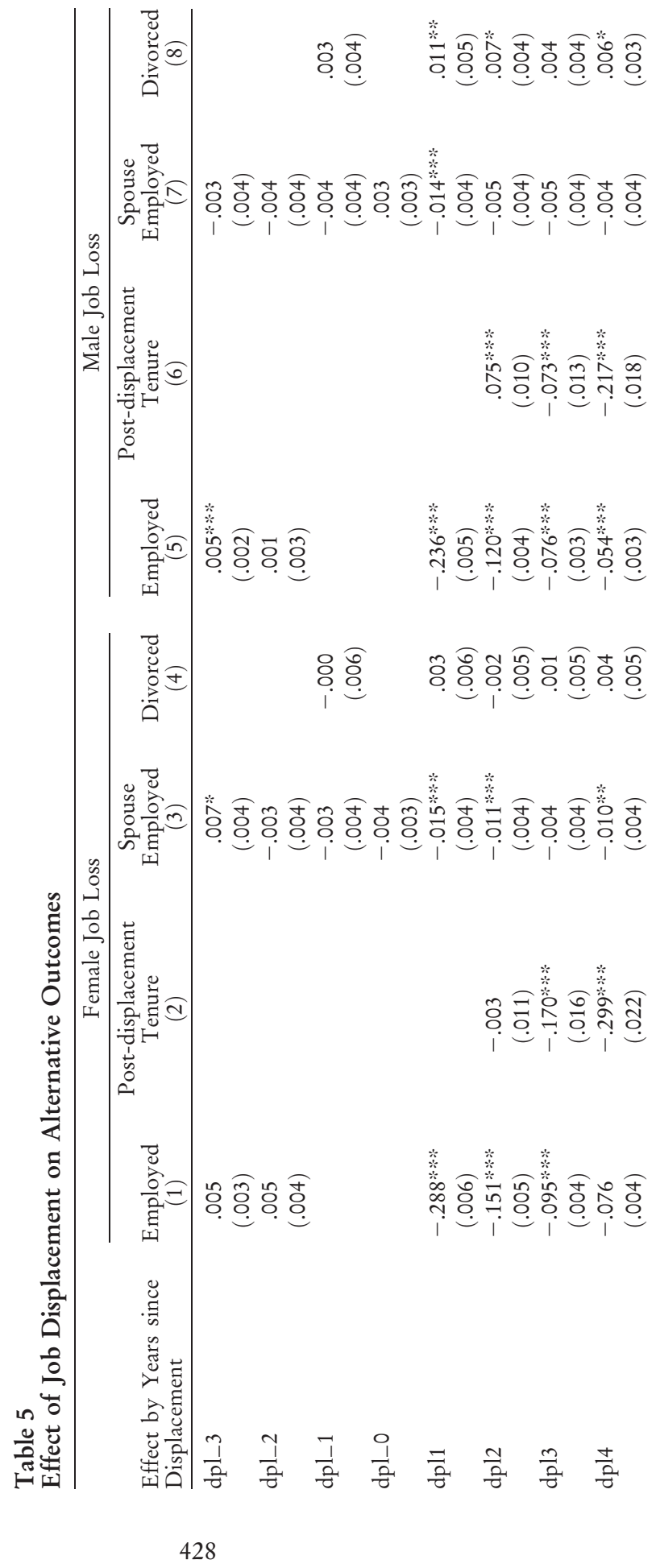

This content downloaded from 130.234.241.107 on January 09, 2017 02:41:12 AM All use subject to University of Chicago Press Terms and Conditions (http://www.journals.uchicago.edu/t-and-c). 


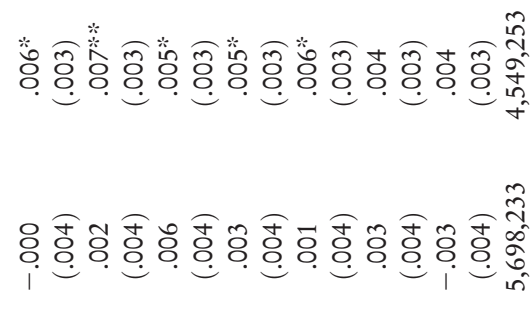

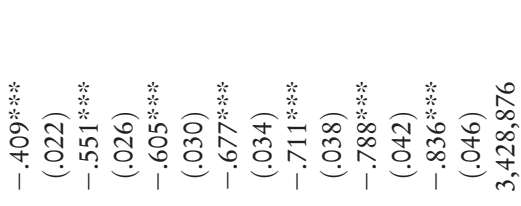

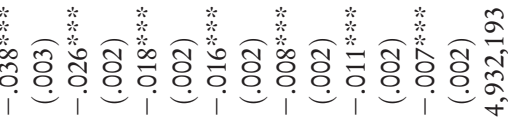

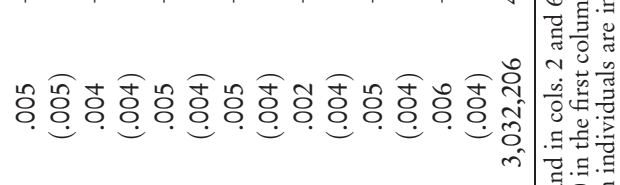

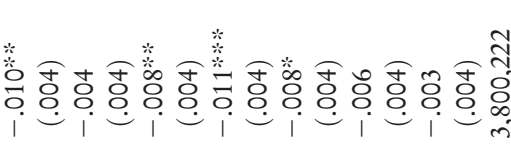

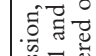

ชิ

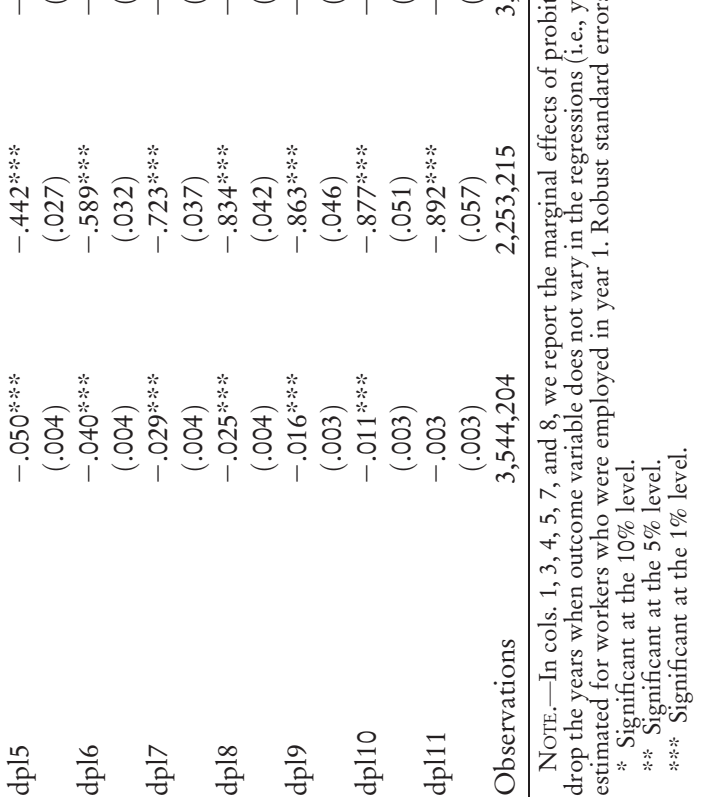


have lower post-displacement tenures in succeeding years than comparison group workers. This indicates that job loss increases job instability.

The third and seventh columns show the effect of job displacement on a spouse's employment. We find that both female and male job losses are associated with a slight reduction in a spouse's employment immediately after job loss. Specifically, there is no indication of the "added worker effect"; that is, a man's job loss does not increase a woman's employment. ${ }^{20}$ The fourth and eighth columns report the effect of job displacement on the probability of separating from the base-year spouse in the years following a job loss. ${ }^{21}$ The results show that male job displacement is associated with an increased risk of divorce.

These results suggest that job displacement has severe and long-lasting consequences on the employment and the employment stability of the affected couples. Since in the previous subsection, we found that only female job displacement significantly affects couples' fertility behavior, the most likely mechanism is the response to a career disruption itself. Females, especially highly educated ones, tend to reduce childbearing after job displacement, since they either fear having trouble finding new employment after a job loss or they want to secure their careers in new jobs before leaving on maternity leave. Low-educated woman are less likely to be reemployed after job displacement, as shown in table A1, and thus they have a much lower opportunity cost of having children.

\section{E. Robustness Analysis}

So far the analysis has focused on married and nonmarried cohabiting couples. The interesting question is whether the results hold if we restrict the sample to married couples only. Figure A1 reports the results for birth outcomes for married couples, using the number of children by the time period as the dependent variable. Female job loss results in a significant drop in fertility in the years immediately following job loss. The magnitude is similar to those of all cohabiting women. As previously, male job loss has no significant effect on fertility.

Another concern with our current analysis is the fact that closing plants are small, and the results using workers in smaller plants may not

20 The evidence on how changes in spouse's employment affect female labor supply is mixed. Juhn and Murphy (1997) suggest that changes in male employment did not explain the increase in married women's employment in the United States during the past decades. However, Stephens (2002) finds some evidence that a man's job displacement increases a woman's employment.

${ }^{21}$ The first coefficient (for year $t-1$ ) captures the pre-displacement difference, i.e., whether displaced workers have shorter relationships than nondisplaced workers. The years $t-3$ and $t-2$ are excluded from this regression, since we do not have spouse codes for years 1988 and 1989, and we are thus not able to define divorce status for years $t-3$ and $t-2$ for base year 1991 workers. 
be generalizable for the whole workforce. In order to check for this, we restrict the sample to workers in bigger plants and use an alternative definition of job displacement: a job loss that occurs because a plant closes down or downsizes significantly (mass layoffs). These results are reported in figure A2 in appendix A. They are in line with the results when using the plant closure definition: female job loss decreases fertility, and male job loss has no effect. Similar to plant closure results, the effect of female mass layoff on fertility was biggest for highly educated workers. ${ }^{22}$ Male workers displaced in mass layoffs seem to have slightly fewer children than nondisplaced workers in the years before displacement. This difference can most likely be explained by employment contract legislations. In some manufacturing industries, the employee contracts require that when employers need to lay off workers for productive reasons, they first have to lay off workers with the least tenure and no children. ${ }^{23}$

As a final robustness check, we extend the analysis to a recovery period to see whether the results obtained using data from the early 1990s, during which Finland experienced a very deep recession, hold for other periods. Figure A3 report the results for base years 1996-98. The results are very similar to the recession period. Female job loss during the recovery years decreases fertility, while male job loss has no effect on fertility. Since the earning losses during recovery years were much smaller, the results again indicate that the fertility responses to female job loss are driven by reasons other than income losses.

\section{Conclusions}

In this study, we have examined how job loss that is due to plant closure affects couples' fertility patterns by following the same couples for more than 15 years. Because job displacement is an exogenous shock to a worker's career, we can estimate the causal effect of this shock on the fertility behavior of couples. Unlike previous studies, we focus on couples and compare how the effect of job displacement varies with spouses' and couples' characteristics. We also studied how job displacement affects couples' other outcomes, such as permanent family income, joint employment decisions, and employment stability and divorce probability. This helps us to better understand the mechanism through which job displacement affects fertility behavior.

${ }^{22}$ In an earlier version of this study, Huttunen and Kellokumpu (2012), we report all the results using both displacement definitions. The results using mass layoff definitions are very similar to plant closure results. The earlier version uses a one-third random sample of females in the FLEED data instead of the total FLEED data.

${ }^{23}$ See the Finnish Federation for Industries and Technology, http://www .teknologiateollisuus.fi/fi/tyomarkkina-asiat/tyoehtosopimukset.html. 
Our results indicate that female job loss decreases completed fertility by $1.8 \%$. The effect is stronger for highly educated women $(2.6 \%)$. Despite the fact that we find that a man's job loss results in a very long lasting and even stronger effect on total family income than a woman's own job loss, it has no effect on completed fertility. When splitting the sample further by pre-displacement education and tenure, we find no evidence that groups with larger income losses after female job loss have stronger fertility responses. This suggests that the possible mechanism through which female job displacement affects fertility is not only the income effect but the difficulties women face in re-establishing their careers after job loss. The only groups for which we find significant responses after male job loss are the couples in which women are well attached to the labor market and couples with the largest estimated income loss: the low-educated high-tenure males.

Our study has contributed to previous research on income and fertility by examining how shocks to permanent family income affect couple's fertility decision at the micro level. Contrary to studies that use exogenous changes in aggregate male income, we do not find that couples react strongly to an income loss generated by male job loss. We also contribute to the literature on the effects of job displacement on fertility by explicitly comparing male and female job losses in similar contexts. Our study is also the first that documents how female and male job displacements affect permanent family income. The results are in line with the study on the effects of female job loss using Austrian data by Del Bono et al. (2012), who also find that a woman's job displacement decreases fertility. However, the fact that we do not find any effect of male job loss on average fertility is in contrast with the study by Lindo (2010), which provides some evidence that male job displacement decreases fertility in the United States. The difference between his and our findings suggests that the effect of job loss on fertility may depend on institutional factors such as the costs of higher education and the access to health care. Also, our study suggests that the mechanism through which job displacement affects fertility may be much more complex than just an income channel. 


\section{Appendix A}

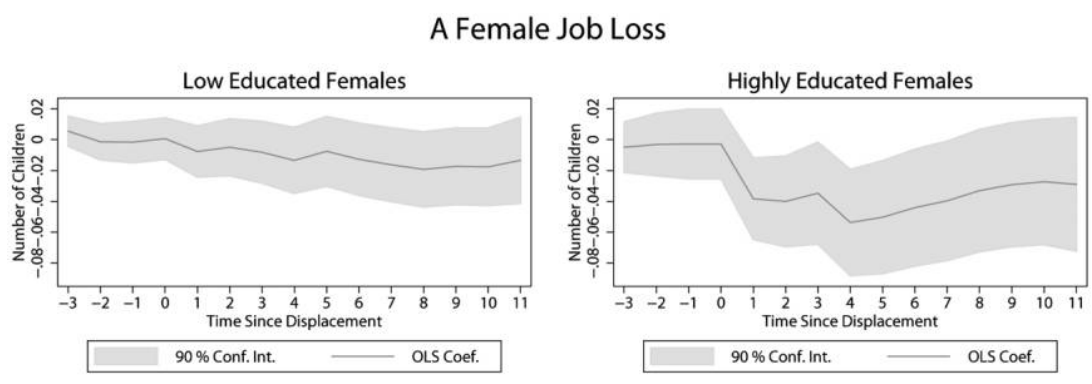

B Male Job Loss
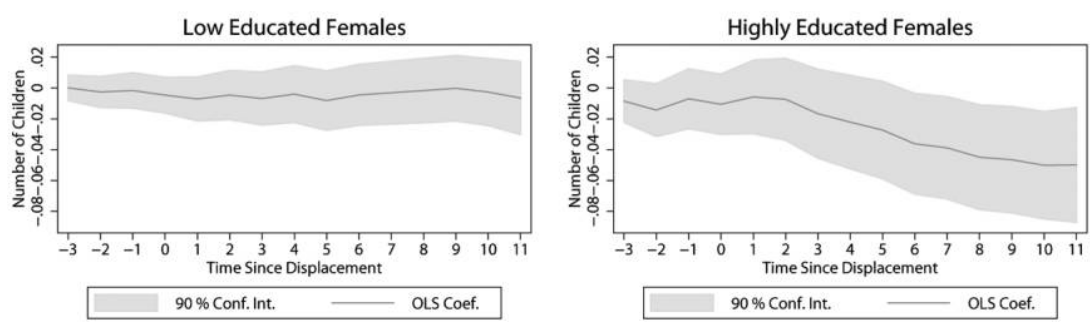

FIG. A1.-Effect of job displacement on fertility for married couples
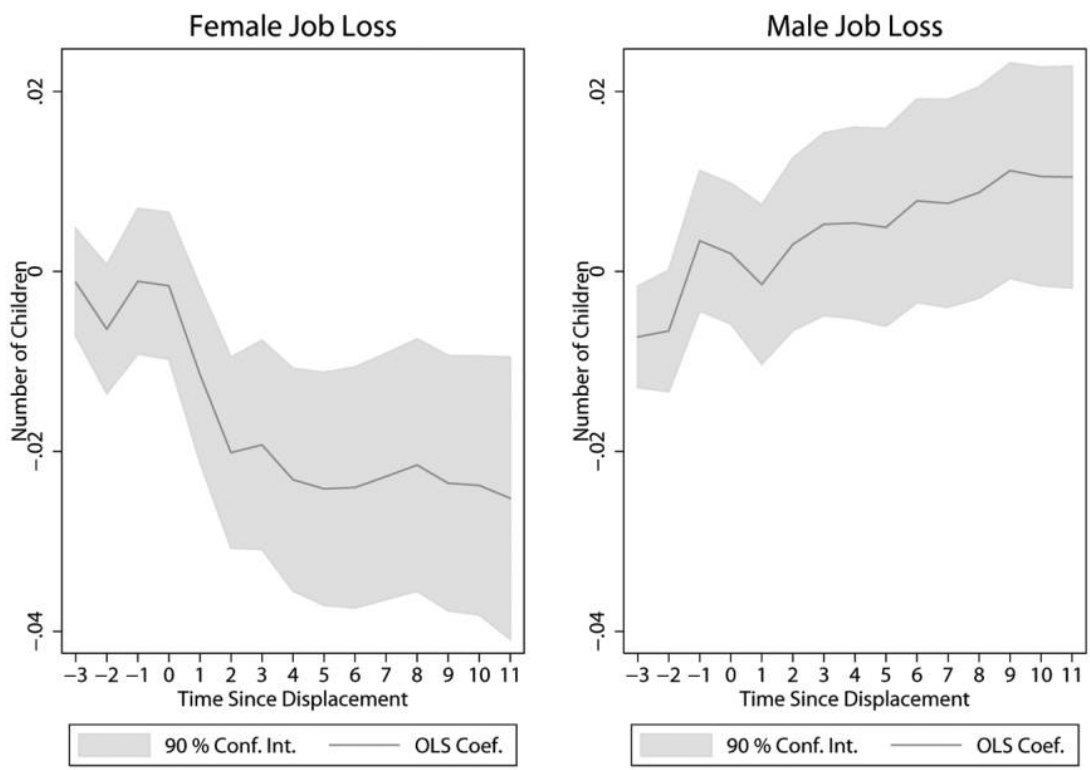

FIG. A2.-Effect of job displacement due to mass layoff on fertility 

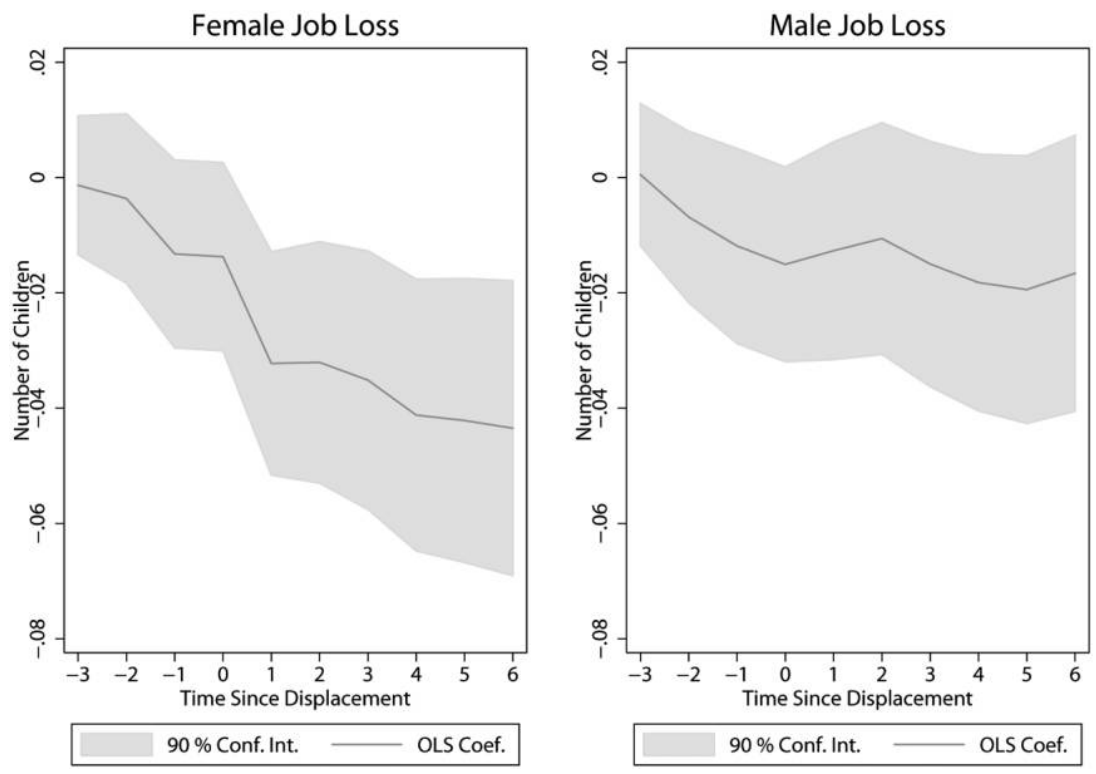

FIG. A3.-Effect of job displacement during recovery period on fertility (years 1996-98). 


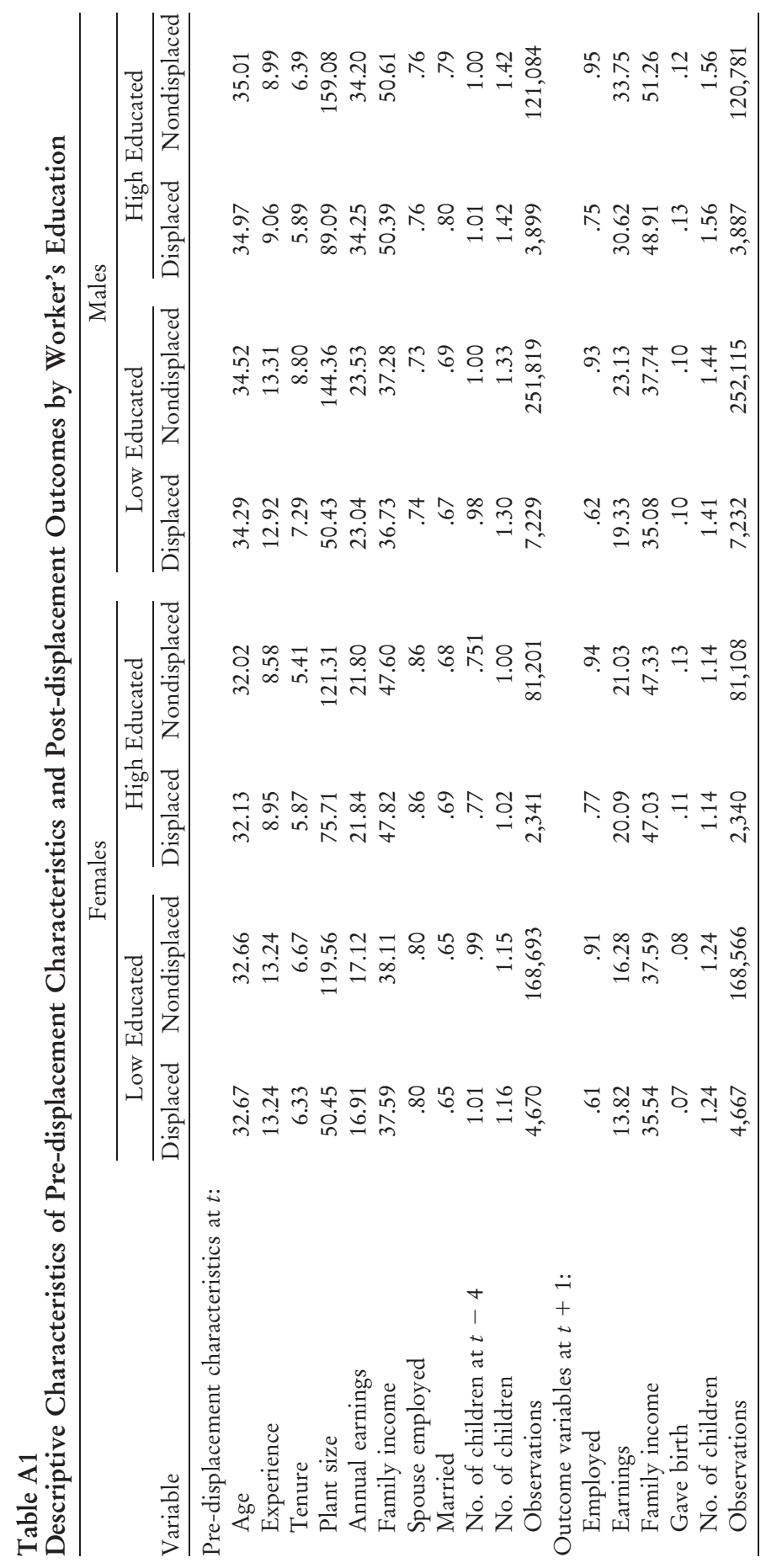




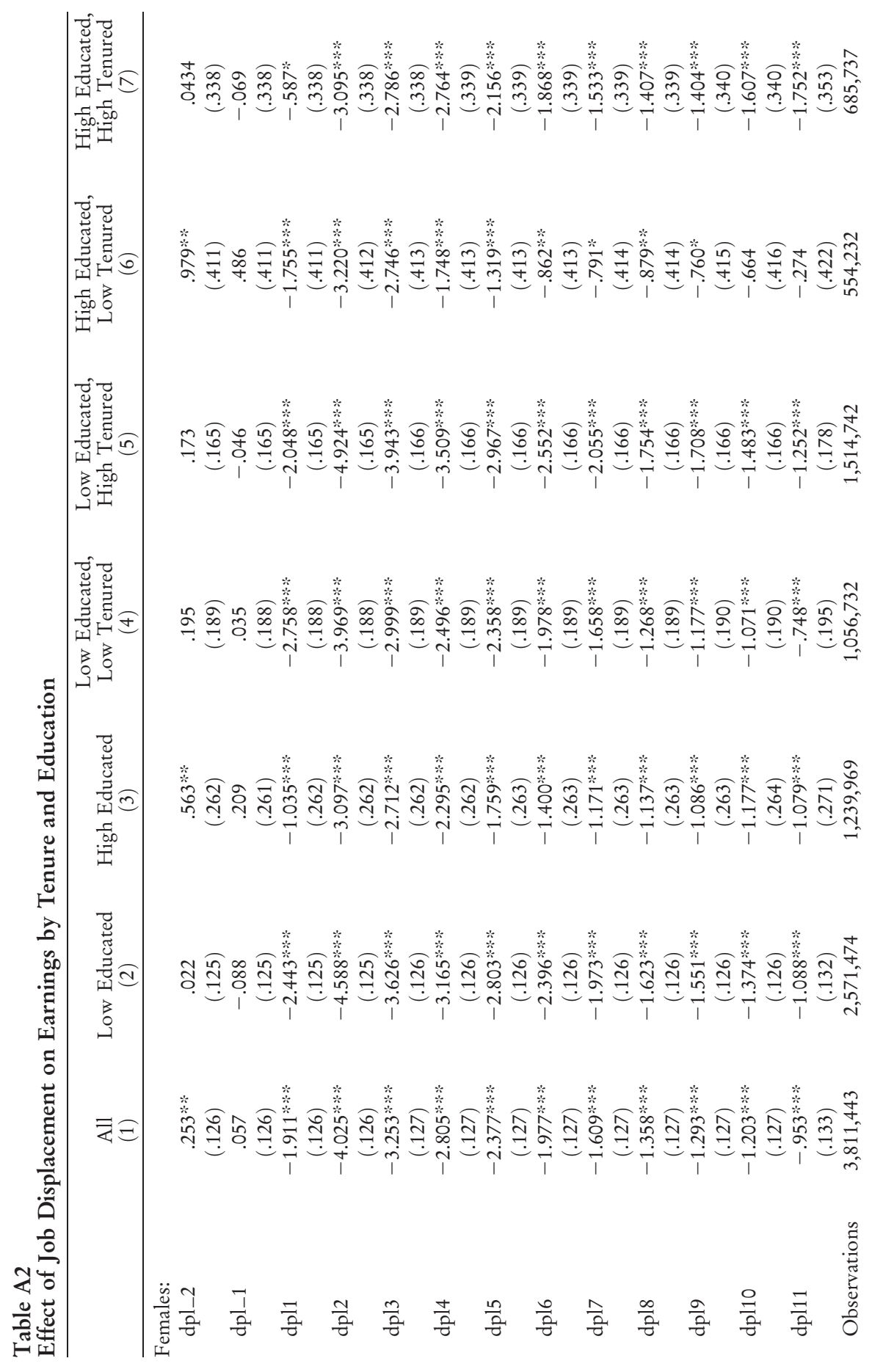




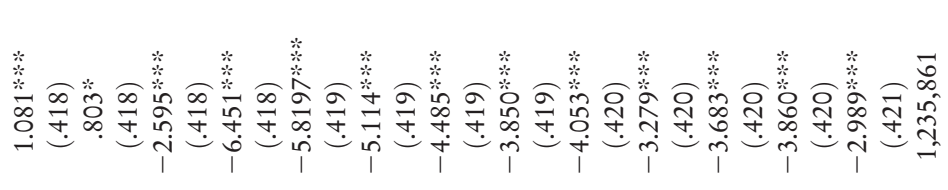

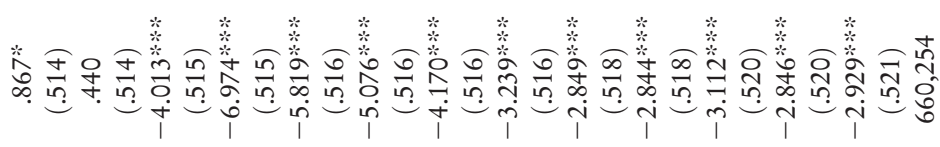

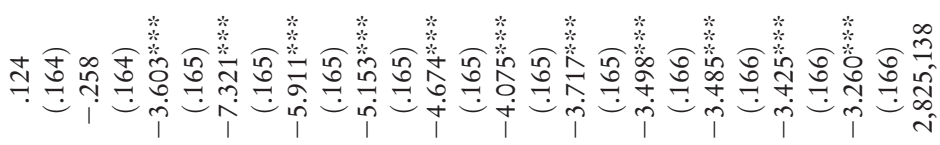

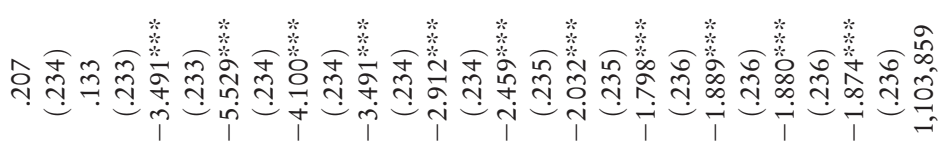

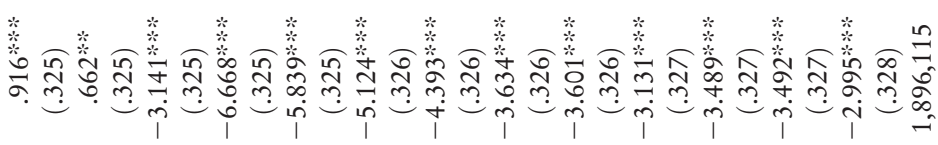

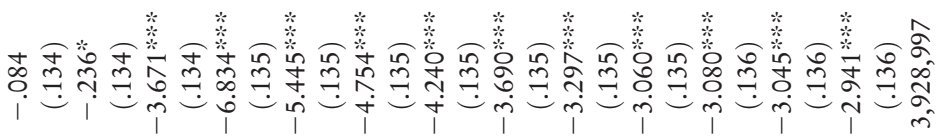

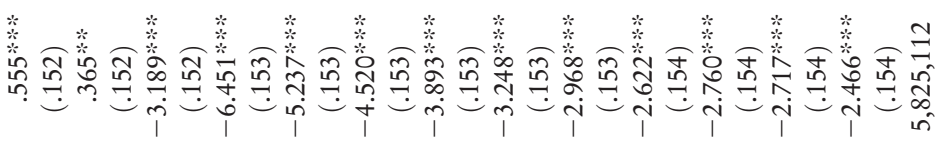

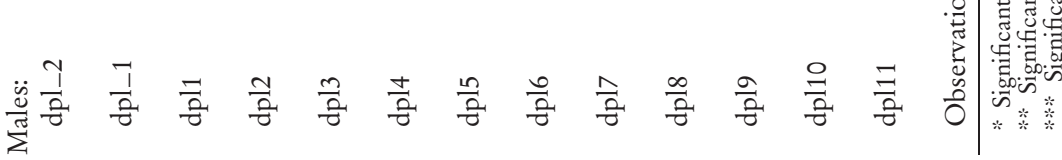




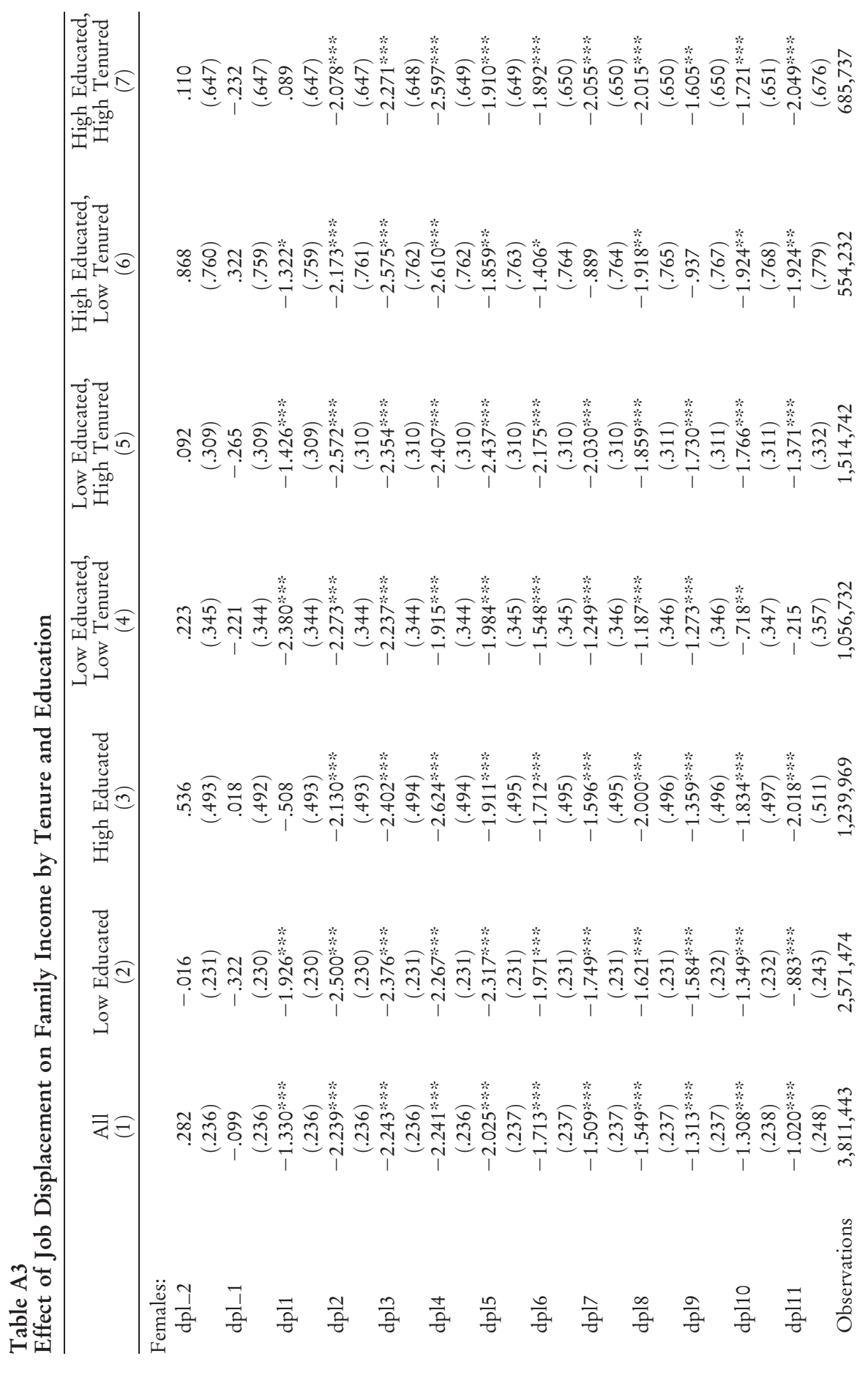




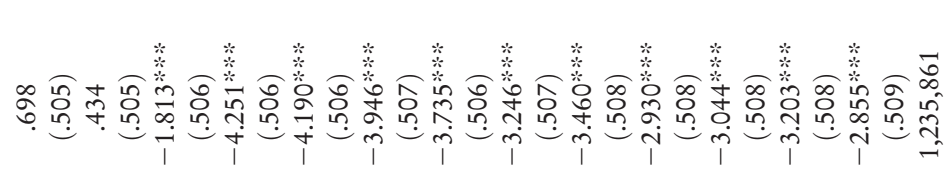

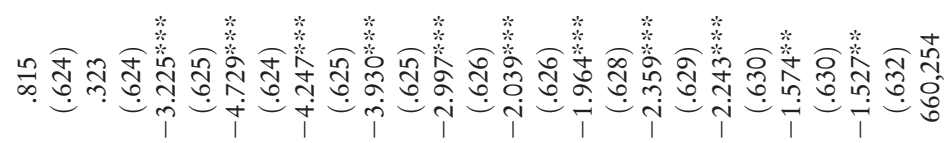

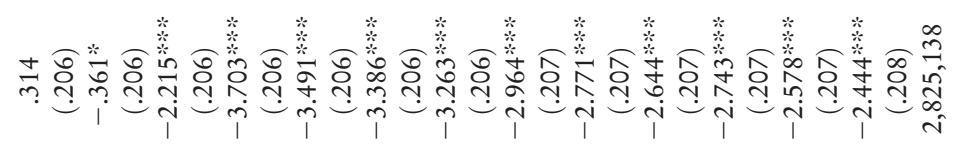

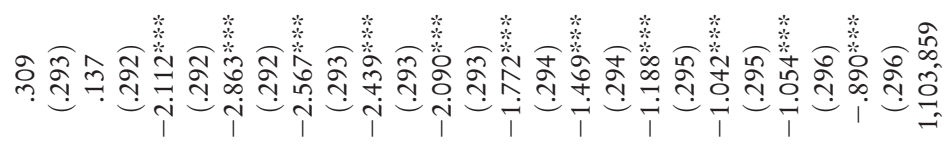

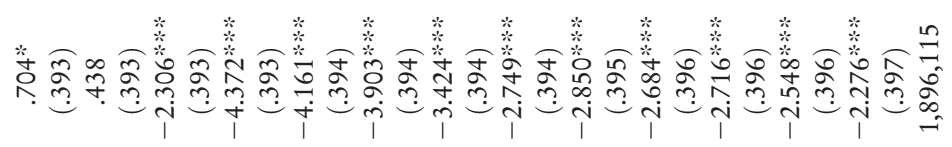

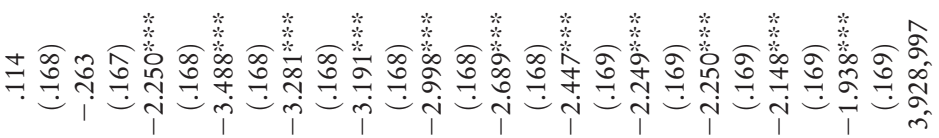

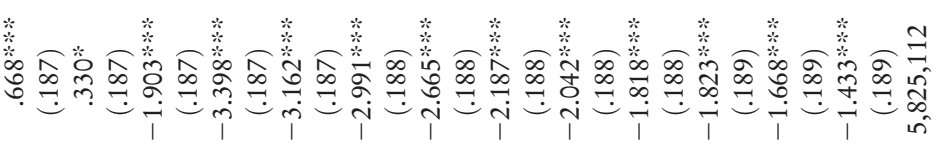

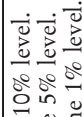

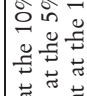

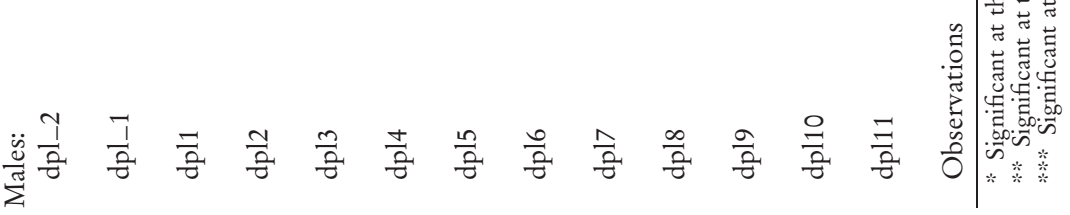




\section{References}

Adda, Jérôme, Dustmann, Christian, and Katrien Stevens. 2011. The career costs of children. IZA Discussion Papers 6201, Institute for the Study of Labor (IZA), Bonn.

Adsera, Alicia. 2005. Vanishing children: From high unemployment to low fertility in developed countries. American Economic Review 95, no. 2:189-93.

Ahn, Namkee, and Pedro Mira. 2001. Job bust, baby bust? Evidence from Spain. Iournal of Population Economics 14, no. 3:505-21.

Becker, Gary A. 1960. An economic analysis of fertility. In Demographic and economic change in developed countries: A conference of the universities, ed. Gary S. Becker, James S. Duesenberry, and Bernard Okun, 225-56. Princeton, NJ: University of Princeton Press.

- 1965. Theory of the allocation of time. Economic Iournal 75, no. 299:493-517.

Becker, Gary A., and Gregg H. Lewis. 1973. On the interaction between the quantity and quality of children. Lournal of Political Economy 81, no. 2, pt. 2:S279-S288.

Black, Dan A., Natalia Kolesnikova, Seth G. Sanders, and Lowell J. Taylor. 2013. Are children "normal”? Review of Economics and Statistics 95, no. 1:21-33.

Browning, Martin, Anne Moller Dano, and Eskil Heinesen. 2006. Job displacement and stress-related health outcomes. Health Economics 15, no. 10:1061-75.

Charles, Kerwin Kofi, and Melvin Stephens. 2004. Disability, job displacement, and divorce. Lournal of Labor Economics 22, no. 2:489-522.

Cohen, Alma, Rajeev Dehejia, and Dmitri Romanov. 2013. Financial incentives and fertility. Review of Economics and Statistics 95, no. 1:1-20.

Couch Kenneth A., and Dana W. Placzek. 2010. Earnings losses of displaced workers revisited. American Economic Review 100, no. 1:572-89.

Davis, Steven J., and Till von Wachter. 2011. Recessions and the costs of job loss. Brookings Papers on Economic Activity 43, no. 2:1-72.

Dehejia, Rajeev, and Adriana Lleras Muney. 2004. Booms, busts, and babies' health. Ouarterlv Iournal of Economics 119, no. 3:1091-1130.

Del Bono, Emilia, Andrea Weber, and Rudolf Winter-Ebmer. 2012. Clash of career and family: Fertility decisions after job displacement. Lournal of the European Economic Association 10, no. 4:659-83.

Eliason, Marcus. 2012. Lost jobs, broken marriages. Iournal of Population Economics 25, no. 4:1365-97.

Eliason, Marcus, and Donald Storrie. 2006. Latent or lasting scars: Swedish evidence on the long-term effects of job displacement. Iournal of Labor Economics, 24, no. 4:831-56. 
- 2009. Does job loss shorten life? Lournal of Human Resources 44, no. 2:277-302.

Farber, Henry. 2007. Job loss and the decline in job security in the United States. Industrial Relations Section Working Paper no. 520, Princeton University.

Gronau, Reuben. 1977. Leisure, home production, and work: The theory of the allocation of time revisited. Lournal of Political Economy 85, no. 6:1099-1123.

Heckman, James J., and James R. Walker. 1990. The relationship between wages and income and the timing and spacing of births: Evidence from Swedish longitudinal data. Econometrica 58, no. 66:1411-41.

Hotz, Joseph V., Jacob Alex Klerman, and Robert J. Willis. 1993. The economics of fertility in developed countries. In Handbook of population and family economics, ed. Mark R. Rosenzweig and Oded Stark, 275-348. Amsterdam: Elsevier.

Huttunen, Kristiina, and Jenni Kellokumpu. 2012. The effect of job displacement on couples' fertility decisions. IZA Discussion Papers 6707, Institute for the Study of Labor (IZA), Bonn.

Huttunen, Kristiina, Jarle Møen, and Kjell G. Salvanes. 2011. How destructive is creative destruction? Effects of job loss on job mobility, withdrawal and income. Lournal of the European Economic Association 9 , no. 5:840-70.

Jones, Larry E., and Michèle Tertilt. 2008. An economic history of fertility in the United States, 1826-1960. In Frontiers of family economics, vol. 1, ed. Peter Rupert, 165-230. Bingley, UK: Emerald Group.

Jacobson, Louis S., Robert J. LaLonde, and Daniel G. Sullivan. 1993. Earnings losses of displaced workers. American Economic Review 83, no. 4:685-709.

Juhn, Chinhui, and Kevin M. Murphy. 1997. Wage inequality and family labor supply. Lournal of Labor Economics 15, no. 1:72-97.

Lindo, Jason. 2010. Are children really inferior goods? Evidence from displacement-driven income shocks. Lournal of Human Resources 45, no. 2:301-27.

Lovenheim, Michael F., and Kevin J. Mumford. 2013. Do family wealth shocks affect fertility choices? Evidence from the housing market. Reviere of Economics and Statistics 95, no. 2:464-75.

Martikainen, Pekka., Netta Mäki, and Markus Jäntti. 2007. The effects of unemployment on mortality following workplace downsizing and workplace closure: A register-based follow-up study of Finnish men and women during economic boom and recession. American Iournal of Epidemiology 165, no. 9:1070-75.

Milligan, Kevin. 2005. Subsidizing the stork: New evidence on tax incentives and fertility. Review of Economics and Statistics 87, no. 3:539-55. 
Perry, Cynthia D. 2004. Economic well-being of the family. PhD diss., Massachusetts Institute of Technology.

Rege, Mari, Kjetil Telle, and Mark Votruba. 2007. Plant closure and marital dissolution. Discussion paper no. 514, Research Department, Statistics Norway.

Schultz, Paul T. 1985. Changing world prices, women's wages, and the fertility transition: Sweden, 1860-1910. Journal of Political Economy 93, no. 6:1126-54.

Sobotka, Tomáš, Vegard Skirbekk, and Dimiter Philipov, 2011. Economic recession and fertility in the developed world. Population and Development Review 37, no. 2:267-306.

Stephens, Melvin, Jr. 2002. Worker displacement and the added worker effect. Lournal of Labor Economics 20, no. 3:504-37.

Stevens, Ann H. 1997. Persistent effects of job displacement: The importance of multiple job losses. Lournal of Labor Economics 15, no. 1, pt. 1:165-88.

. 2001. Changes in earnings instability and job loss. Industrial and Labor Relations Review 55, no. 1:60-78.

Sullivan, Daniel, and Till von Wachter. 2009. Job displacement and mortality: An analysis using administrative data. Ouarterly Iournal of Economics 124, no. 3:1265-1306.

Topel, R. H. 1990. Specific capital and unemployment: Measuring the costs and consequences of job loss. Carnegie Rochester Conference Series in Public Policv, no. 33, 181-214.

von Wachter, Till, and Elizabeth Weber Handwerker. 2010. Variation in the cost of job loss by worker skill: Evidence using matched data from California, 1991-2000. Department of Economics Discussion Paper Series, Columbia University. 